\title{
Las formas de ocupación rural en Hispania. Entre la terminología y la praxis arqueológica ${ }^{1}$
}

\section{Rural occupation modalities in Hispania. Between terminology and archaeological praxis}

\author{
Carmen Fernández Ochoa \\ Universidad Autónoma de Madrid \\ carmen.fernandez@uam.es \\ Javier Salido Dominguez ${ }^{2}$ \\ Escuela Española de Historia y Arqueología en Roma-CSIC \\ Mar Zarzalejos Prieto \\ Universidad Nacional de Educación a Distancia-UNED
}

Recibido 06/02/2014

Aceptado 28/08/2014

\section{Resumen}

En las últimas décadas, el estudio de las formas de ocupación rural ha adquirido un papel protagonista en el marco del análisis de los paisajes antiguos. En este trabajo expondremos una síntesis sobre las diferentes vías de investigación abiertas sobre este asunto, con la finalidad de ofrecer una visualización rápida y eficaz sobre uno de los temas más complejos que la Arqueología romana tiene hoy en día planteados.

Palabras clave: paisaje antiguo, implantación romana, villae, establecimientos rurales, vicus, aglomeraciones secundarias, explotaciones agropecuarias.

\begin{abstract} plex issue of Roman Archaeology nowadays. Roman farms.

\section{INTRODUCCIÓN}

Los estudios sobre las formas de ocupación rural en el mundo romano no gozan de una gran antigüedad pero, desde fines de los años 70 del pasado siglo, han ido adquiriendo un volumen e intensidad tales que les confiere un papel estelar dentro de las trayectorias historiográficas de algunas de las más importantes escuelas de la arqueología occidental. Si comparamos los estudios sobre el espacio rural hispanorromano con la
\end{abstract}

The study of the rural occupation modalities has played a major role within the analysis of ancient landscapes over the last decades. This paper sheds light into current research lines on this field, offering an insight into a most com-

Key words: Ancient landscapes, Roman settlements, villae, rural settlements, vicus, secondary agglomerations,

1 Este trabajo se ha realizado en el marco del proyecto Territorio, jerarquías y estructuras socio-Económicas en la vertiente norte de Sierra Morena (MINIVS) (HAR201234422) dirigido por M. Zarzalejos. Igualmente, se enmarca en el Proyecto de I+D: Paisajes de dominación y resistencia. Procesos de apropiación y control social y territorial en el Noroeste hispano (Padore) (HAR 2012-33774) dirigi- documentación generada por la historiografía de otras regiones del Occidente romano se advierte un cierto retraso en el conocimiento de los paisajes rurales de Hispania. No obstante, en los últimos años, se van acortando distancias al igual que ha sucedido con la investigación sobre los centros urbanos, cuyo despegue está permitiendo la verificación comparativa entre los núcleos urbanos hispanos y los de otras provincias romanas.

do por A. Orejas Saco del Valle. Ambos proyectos han sido concedidos por el MINECO.

2 Contratado del CSIC en la Escuela Española de Historia y Arqueología en Roma, en la modalidad JAE-Doc del Programa «Junta para la Ampliación de Estudios» cofinanciada por el Fondo Social Europeo. 
A favor de este avance debemos señalar el progreso experimentado por las técnicas de investigación arqueológica y la multiplicación de las excavaciones realizadas en nuestro país, que han proporcionado un enorme volumen de reciente y cada vez más precisa documentación arqueológica, que ha supuesto el rechazo de la visión tradicional que concebía el paisaje rural romano como un espacio perfectamente ordenado y explotado económicamente por la elite romana desde sus villae. Dicho progreso ha permitido superar esta percepción simplista del poblamiento rural predominante hasta los años 90 , de tal modo que, en la actualidad, el mundo rural está siendo analizado a través de una nueva óptica mucho más positiva, compleja y rica, presidida por el amplio concepto de "formas de ocupación rural". Si bien la investigación actual sigue ocupándose preferentemente del estudio de la arquitectura campesina y trata de definir conceptualmente el término villa, se ha ido superando esa imagen tan arraigada de que el campo en época romana estaba poblado solamente por estos centros que aunaban las funciones residenciales y de explotación agrícola. Así, desde el punto de vista teórico, contamos ya con un grupo significativo de trabajos que han desterrado la idea de la villa como la única forma de explotación rural, destacando la existencia de otras formas de ocupación rural que, sin embargo, resultan difíciles de diferenciar en su materialidad desde el punto de vista arqueológico. Por ello, nos proponemos en estas páginas introducir algunos elementos para la reflexión a través de un acercamiento actualizado a la información textual, epigráfica y arqueológica, que sirva como punto de partida para afrontar este tema de enorme importancia en los estudios hispanorromanos. En este sentido, también deseamos poner de manifiesto que uno de los objetivos de esta aportación nace de nuestra propia experiencia docente e investigadora. Los estudiantes de arqueología y muchos jóvenes investigadores recién graduados se enfrentan al estudio del mundo rural romano a través de la realización de Cartas Arqueológicas, evaluaciones de impacto ambiental, trabajos de fin de Grado o de fin de Máster, etc. sin unas ideas básicas y prácticas acerca de la complejidad del paisaje rural hispanorromano lo que conduce, en ocasiones, a la obtención de resultados escasamente positivos o, incluso, a la formulación de propuestas interpretativas fundamentadas en presupuestos conceptuales erróneos. Aunque el tema que presentamos en este homenaje a Katia Galán no coincide con sus líneas de investigación, lo hemos orientado hacia un interés didáctico en aras de converger con nuestra compañera en su apuesta continuada por fomentar el desarrollo de los aspectos prácticos en la enseñanza universitaria.
2. UNA APROXIMACIÓN SINTÉTICA A LAS INVESTIGACIONES SOBRE LAS FORMAS DE OCUPACIÓN RURAL ROMANAS EN HISPANIA

1. Una importante línea de trabajo sobre el mundo rural romano ha consistido en la investigación acerca de las unidades ocupacionales recogidas por la literatura clásica y la epigrafía (Curchin 1985; Le Roux 1992-93; Martínez Gázquez 2008, entre otros). En realidad, este tipo de estudios constituyen el fundamento básico e imprescindible para acceder al conocimiento de las diversas entidades de ocupación, de su formulación jurídica y su evolución en el tiempo. Como avanzábamos más arriba, en este terreno tiene particular protagonismo el concepto de villa, que capitaliza numerosos trabajos en la historiografía general, seguido de los términos vicus y castellum (Tarpin 2002; Orejas y Ruíz del Árbol 2010; Aounallah 2010).

El estudio detallado de las fuentes escritas nos informa de la existencia, en época altoimperial, de numerosos tipos o formas de ocupación que se encuentran estrechamente relacionados con la organización y el control del territorio. Aunque el pagus es la organización territorial base del sistema donde se encuentran los diferentes asentamientos que conforman el paisaje rural de época romana (castella, vici, fora, conciliabula, etc), éstos también participan del fenómeno de la urbanización, siendo solamente "menores" desde el punto de vista administrativo con respecto a la capital (Pérez Losada 1996: 190; Martínez Melón 2006: 127). En cambio, este sistema de implantación territorial comienza a transformarse durante el siglo III d.C., momento en que la civitas pierde gran parte de su autonomía y, derivado de la paulatina y creciente concentración de la propiedad por parte de las aristocracias locales, aparecen nuevas realidades en el territorio a favor de hábitats secundarios tipo castrum, oppidum y castellum, así como locus, villare y villulae, adaptados a circunscripciones administrativas con una clara finalidad fiscal (Durliat 1990: 152-157; Martínez Melón 2006). El desarrollo de estas entidades significa un cambio teórico en la distribución de la población, posiblemente a costa de entidades mayores como el vicus.

La historiografía anglosajona comenzó denominando a las agrupaciones rurales de mayor entidad small towns (Todd 1970; Burnham y Wacher 1990) y la francesa agglomerations secondaires (Maurin 1990; Petit y Mangin 1994; Massy 1997; Aupert, Fincker y Tassaux 1998; Fiches 2002), de donde la historiografía española ha adoptado la nomenclatura. No obstante, bajo este concepto general y otros que aluden a lugares de menor entidad se engloban diferentes formas de ocupación que la investigación tiende a denominar con términos actuales heterogéneos que resultan difíciles de aunar en la discusión científica e incluso, en ocasiones, de adscribir a realidades arqueológicas concretas. Es el caso de las denominaciones que encontramos en obras de reciente publicación donde las diferentes 
formas de ocupación rural aparecen identificadas como fermes, sites modestes, villages, bourgs en la historiografía francesa (Colleoni, Petit y Sillières 2013: 217), quintas, casais y abrigos en la portuguesa (Bugalhão 1998). En el ambiente hispano, se emplean definiciones como complejos de grandes dimensiones (de 2000 a $3000 \mathrm{~m}^{2}$ ) o bien edificios de menores dimensiones y complejidad, edificios aislados, centros artesanales (Busquets, Moreno y Revilla 2013). A pesar de los esfuerzos encomiables realizados por los especialistas a la hora de unificar una terminología que resulta muy difusa, no debemos olvidar que tanto los testimonios epigráficos como las fuentes escritas nos han transmitido términos latinos que sería deseable adscribir a las diferentes realidades arqueológicas de las formas de ocupación del campo en época romana. Por nuestra parte, en esta aportación hemos reelaborado un Apéndice terminológico con fines eminentemente prácticos y formativos, al que hemos añadido los términos que hacen referencia a los establecimientos relacionados con las vías, tal y como planteó en su día Leveau (2002), considerando que se trata también de fórmulas de ocupación rural, a pesar de que no suelen ser conceptualizadas de este modo en la bibliografía hispana que aborda esta cuestión. Cada uno de los términos del Apéndice parte de una definición original contenida en las fuentes textuales a la que se agregan la información epigráfica y la ejemplificación arqueológica, siempre que sea necesaria para explicar materialmente la línea que sustenta la identificación correspondiente.

2. Una segunda vía analítica se ha preocupado, por el contrario, de indagar en las relaciones de estas entidades reflejadas en las fuentes y su posible correlación con la materialidad arqueológica a partir de los restos exhumados. Dentro de los estudios arqueológicos sobre las formas de ocupación del espacio agrario, ocupa un papel preponderante el modelo de las villae, sobre todo, de las tardías y su relación con el fundus. La definición de la villa romana, objeto de estudio de numerosos trabajos de investigación, sigue resultando todavía en la actualidad, un concepto tan general que en ocasiones carecemos de los argumentos necesarios que nos permitan determinar con precisión su verdade-

3 Serv. Georg. 2, 382; Plaut. rud. 33-34; Ps. Quint. Decl. Mai. XIII, 2; Letta 2005: 89-90.

4 Numerosos especialistas tienden a definir todos los establecimientos rurales como villae (Smith 1997).

5 Ferdière trató de identificar la villa romana desde un punto de vista arquitectónico, definiéndola como "une exploitation agricole comportant une partie résidentielle plus o moins importante, et construite 'en dur' a la manière romaine" (1988 (1): 158). Esta propuesta ha sido discutida por otros autores (Leveau et alii 1999).

6 Gros (2001) aborda la cuestión planteando su función como una "structure de domination et de profit" así como una ro significado y su aplicación a la hora de identificar dicho concepto con los restos materiales aparecidos. Como es lógico, un lugar común en la mayor parte de las definiciones al uso es la ubicación extraurbana de esta forma de ocupación pero, a partir de esta consideración, resulta difícil encontrar una acepción unánime, precisamente porque las referencias rastreables en la propia tradición clásica no son tan esclarecedoras como sería de esperar (Sfameni 2006: 10). De hecho, una parte de los estudios sobre este particular comienzan haciéndose eco de la dificultad de aplicar el término villa a un tipo concreto de estructura en el ámbito rural, ya que, según indicó en su día J.G. Gorges (1979: 11), los romanos no emplearon un solo término para designar lo que podría ser una explotación agrícola o una mansión más o menos lujosa enclavada en el campo.

Indudablemente, la estrecha asociación entre el pagus y la presencia de villae, que es la condición esencial para su existencia ${ }^{3}$, ha llevado a considerar que el paisaje rural romano, como ya hemos comentado, estaba ocupado principalmente por villae ${ }^{4}$. Concebidas como una simple granja, como un centro de explotación rural ${ }^{5}$ (definidas en la bibliografía germánica como villae rusticae) o simplemente como un lugar placentero de ocio ${ }^{6}$ o una residencia imperial en el campo, la villa puede ser confundida con otras formas de ocupación rural, tales como los vici, villare, las villulae, sin olvidar los praedia que conocemos por las inscripciones aparecidas cerca de Caesarea en Mauritania ${ }^{7}$ y en las fuentes escritas ${ }^{8}$ que se refieren tanto a propiedades rurales como urbanas.

Planteada la dificultad para definir la villa, que tradicionalmente se ha considerado la unidad básica de explotación agrícola del territorio, debemos cuestionarnos hasta que punto podemos aplicar el concepto de villa a las diferentes realidades materiales localizadas en el ámbito rural hispanorromano. Esta aplicación terminológica se complica si tenemos en cuenta que este concepto, en época bajoimperial, comporta un sentido territorial, formando parte de la subdivisión administrativa de la civitas $^{9}$. Así pues, la villa podría ser definida desde el punto de vista constructivo por la aparición de uno o varios edificios (residenciales y agríco-

"structure de plaisance"; por su parte, Lafon (2001) ha estudiado en detalle las villae maritimae y "lacustres" construidas por la aristocracia romana entre finales de la República y comienzos del Imperio para el descanso y el ocio placentero.

7 Veánse las recogidas en Leveau 1984: 280-282; Pucci 1989: 114-115.

8 Así por ejemplo en Lengrand 1996.

9 Columela (De agr. 1, 4, 8) y Plinio $(N H, 18,6,1)$ afirman que la villa es el edificio del fundus y Varrón (rust. 3, 2, 5) vincula villa con gran propiedad. Del mismo modo, el Digesto (1, $16,211)$ define el fundus como ager con aedificium y este edificio con villa (Martínez 2006: 122). 
las) pero, desde la perspectiva fiscal, la villa constituye una circunscripción administrativa inferior a la del vicus ${ }^{10}$. El espacio de la villa responde a una lógica de apropiación privada de una parte del suelo para la producción y residencia, y en segundo término, para la circulación que los possesores gestionan con fines especulativos, de modo que de centros de gestión de un territorio pudieron llegar a convertirse en verdaderos centros de administración fiscal y control de una circunscripción ${ }^{11}$. Esta dificultad para definir con precisión muchas de las estructuras exhumadas como villae ha supuesto una cierta generalización en la bibliografía más reciente de la denominación de "establecimientos rurales" $"$.

El vicus, en cambio, está constituido por un hábitat agrupado o aglomeración que ofrece servicios administrativos, con sus propios magistri, praefecti y cargos municipales (Leveau 1993: 469), así como servicios económicos o religiosos y otros relacionados con las vías de comunicación (Grenier 1934). A partir del estudio exclusivamente epigráfico de las inscripciones aparecidas, se han planteado criterios de identificación de los vici hispanorromanos, que se distinguen por presentar una cierta autonomía en cuanto al control y administración del territorio, una génesis claramente indígena, un cierto carácter religioso y una mayor concentración en zonas menos romanizadas (Curchin 1985: 332-338), pero continuamos sin definir con claridad el perfil arqueológico de un vicus. Analizados desde el punto de vista teórico parece que existen diferencias hipotéticas entre las villae y los vici, pero podemos preguntarnos si tales distinciones se pueden percibir en el nivel constructivo o material. No cabe duda de que la realidad es mucho más compleja (Bertoncello 2002; Garmy 2002).

Si centramos nuestra atención en los testimonios de villae documentados en Hispania, cabe afirmar que hasta fechas recientes, las villas hispanas, como la mayoría de las excavadas en todo el Imperio $^{13}$ se han estudiado en función de los aspectos arquitectónicos y decorativos de la pars urbana mientras las partes rusticae resultaban prácticamente desconocidas, con alusiones breves a las zonas productivas y a los fundi con vagas explicaciones sobre la riqueza del entorno (Fernández Ochoa, Gil Sendino y Orejas 2004). No obstante, las intervenciones arqueológicas en las villas

10 Así lo desarrolla Durliat 1990: 153.

11 A este propósito puede verse Pellecuer 2000.

12 Véase Van Ossel 1992: 39.

13 La ingente bibliografía existente sobre este particular resulta imposible de reseñar en este artículo. Cf. Baldini 2001; Lewit, 2004; Gros 2006; Sfameni 2006; Ortalli 2006; Bowes 2010.

14 En los ultimos años se han constituído grupos de investigación dedicados al estudio del mundo rural romano, muchos peninsulares han generado un amplio elenco informativo cuyas referencias regionales han sido reseñadas, hasta finales de los años 90, en compendios bibliográficos específicos (Chavarría 1999; Fernández Ochoa y Morillo 2005). La última década, por su parte, ha sido pródiga en estudios monográficos de villae tal y como reflejan algunos trabajos de síntesis (Chavarría 2005, Chavarria, Arce y Broggiolo 2006) y, sobre todo, se han celebrado numerosas reuniones científicas de carácter monográfico. A título de ejemplo cabe citar las jornadas realizadas en el año 2003 (Noguera 2010), el congreso de Gijón del 2006 (Fernández Ochoa, Gil Sendino y Garcia-Entero 2008), así como los de Tarragona en el 2006 (Remolá 2007), Lérida en el 2007 (Revilla, Gonzalez Pérez y Prevosti 2008 y 2010), Barcelona en el 2010 (Fiches, Plana-Mallart y Revilla 2013), Cádiz en 2012, Piazza Armerina también en el 2012 o Sevilla en 2014. En esta misma línea debemos anotar la serie sucesiva de monografías sobre villae publicadas por el ICAC, a las que cabe añadir nuevas perspectivas sobre estudios regionales de conjunto como la tesis de Fornell (2005) sobre villas béticas, la monografía de Teichner (2008) sobre las lusitanas o las reflexiones de Regueras acerca de las villas del Duero $(2013)^{14}$. En mucha menor medida se han investigado los aspectos socio-económicos de estas propiedades fundiarias si bien cada vez proliferan más trabajos sobre las partes rusticae de las villas, concretamente en relación con las áreas productivas (Peña Cervantes 2010; Salido 2003-2004; 2008 Fernández Ochoa et alii 2012), siendo la investigación sobre la caracterización y el territorio de los fundi un tema todavía pendiente (Orejas y Ruíz del Árbol 2008).

En cuanto a los vici, no son muchos los restos arqueológicos hallados en la Península Ibérica que se puedan interpretar como tales. Sin ánimo de ser exhaustivos, en el Peñon de Ifach se encuentra un asentamiento tipo vicus con vocación económica para la explotación del entorno y que depende de Dianium (Denia) (Abascal et alii 2007). En el noroeste, este tipo de hábitat agrupado ha sido ampliamente tratado por Pérez Losada (Pérez Losada 1996: 189-193 y 2002, passim) y se citan como vici, entre otros, los de Iria Flavia,(Padrón), Tongobriga (Marco de Canaveses), Tude (Tu y) o Vicus Elani (Vigo) (Martins et alii 2005; Rodríguez Resino 2007: 136). Para la región de

de ellos vinculados a proyectos de I+D incardinados en la Universidad o en el CSIC (vid. infra) En junio del 2014 se ha celebrado en Sevilla un Congreso Internacional sobre Las villas romanas de la Betica. En relación con el estudio de las villae adquiere particular relevancia la creación del Centro Interuniversitario di Studi sull'Edilizia abitativa tardoantica en el Mediterraneo (CISEM) dirigido por P. Pensabene y C. Sfameni que trata de integrar a los estudiosos interesados en este tema. 
Riotinto se considera la posible existencia de algún vicus metallus, es decir, agrupaciones propias de la organización territorial vinculada a las explotaciones mineras, con funciones claramente fiscales a modo de cabeceras de comarca (Pérez Macías et alii 2009, 5253). En las proximidades de Carteia (San Roque, Cádiz) se localizó un pequeño vicus alfarero y pesquero-conservero, con sus instalaciones portuarias independientes y su propia necrópolis (Bernal et alii 2004; Blánquez et alii 2005). También se interpretan como un vicus los restos excavados en el yacimiento de Las Madrigueras en los entornos de Segobriga (Cuenca) (Urbina y Morín 2013).

Por lo que respecta a la materialidad contrastada de núcleos rurales vinculados a la red viaria, si se excluyen las mansiones asentadas en centros principales y los vici viarii de mayor envergadura, no son muchos los ejemplos excavados o, al menos, identificados en tal sentido. En las inmediaciones del campamento de Aquis Querquennis (Baños de Bande) es bien conocida la mansio situada junto a la vía XVIII, dotada de un patio murado exterior provisto de pozo y canalillo de conducción de agua (Rodríguez Colmenero et alii 1999: 904-907, fig. 4, lám. 2 y 3). También se ha publicado recientemente la mansio de Ildum (Vilanova d'Alcolea, Castellón), situada a mitad de camino entre las ciudades de Dertosa y Saguntum (Arasa 2013). Algunos yacimientos se han interpretado como mutationes, como la ubicada en la ruta $A b$ Asturica Burdigalam, en Mariturri (Núñez y Sáenz de Urturi 2005; Núñez y Aquilué 2006) o El Beneficio (Collado Mediano, Madrid) (Jiménez Guijarro 2008). Asimismo, en el Tossal de Cal Montblanc (La Noguera, Lleida) se ha identificado, con alguna reserva, una posible statio relacionada con una vía secundaria (Rovira y Gasca 1990). Además se conoce la noticia que nos informa sobre la petición de Simmaco para utilizar los caballos del cursus publicus en Hispania (Symm. Epist. 7, 82; Arce 1990: 36-38).

3. Un tercer camino de investigación pretende, finalmente, ensayar las posibilidades de abordar el estudio y categorización del poblamiento rural romano a partir de métodos prospectivos. Esta vía de trabajo parte del tardío despegue en nuestro país de la Arqueología Espacial en los años 80 y se centró inicialmente en una valoración del territorio a partir de indicadores ecológicos y económicos, orientados a la generación de modelos de poblamiento y a la observación de las pautas de su evolución (Ruiz Zapatero y Burillo 1988). La cristalización de estos planteamientos metodológicos tuvo entre algunas de sus consecuencias la creación de la serie Arqueología Espacial para canalizar la edición de los encuentros sobre este asunto organizados por el entonces Colegio Universitario de Teruel, de la mano de F. Burillo. Entre los frutos heterogéneos de aquellas propuestas de trabajo se hallan algunos planteamientos metodológicos sólidos junto a otros resultados que aplicaron mecánicamente las técnicas de análisis o que cayeron en interpretaciones estereotipadas y discutibles, según valoró ya en su día A. Orejas (1991: 211).

De la mano del paradigma postprocesualista al que se agregó un marcado enfoque humanista, poco después, se abrirá camino en la Arqueología peninsular una visión más holística del estudio territorial que cristaliza en la concepción del paisaje como una construcción social y, como tal, una expresión cultural de las sociedades y de los procesos históricos que lo han modelado. Esta línea conceptual pasó a denominarse Arqueología del Paisaje y tiene en A. Orejas una de sus principales teorizadoras en su aplicación a la Arqueología Hispanorromana (Orejas 1991, 1995-96, 2006, 2008, entre otras). La elaboración teórica y el conjunto de herramientas y aplicaciones metodológicas que sirven de sostén a esta vía de análisis entroncan con los estudios sobre el territorio rural romano emprendidos por la escuela francesa, una parte de cuyos miembros funda en 1991 la asociación AGER. Esta asociación se dedica específicamente a promover la investigación sobre la arqueología y la historia rural de la Galia romana, edita un boletín anual que alberga importantes novedades sobre el estado de la investigación de los paisajes rurales en este territorio y celebra coloquios bianuales sobre estas líneas temáticas. Desde algunos trabajos colectivos de referencia (Favory y Fiches 1994; Pellecuer 1994; 1996; Ouzoulias et alii 2001), la historiografía francesa ha ejercido una importante influencia en la investigación de las formas de ocupación rural en Hispania, como muestra la colaboración científica establecida entre investigadores galos y españoles, que se concreta, por ejemplo, en la coedición de las actas del Coloquio AGER IX, dedicado al estudio de los paisajes rurales y territorios de las ciudades del Occidente romano (Fiches, Plana-Mallart y Revilla 2013).

Aunque es obvio que no podemos hacernos eco de la ingente producción bibliográfica existente sobre este particular, consideramos importante destacar algunas aportaciones al conocimiento de los paisajes rurales que se han sucedido en diferentes ámbitos geográficos de Hispania. Así, en el NE, este tipo de análisis goza de una importante tradición desde los primeros trabajos de M. Prevosti sobre el poblamiento rural del área de Baetulo e Iluro (Prevosti 1981 a y b) y cuenta con algunos hitos bibliográficos como el Simposio sobre villas en la Tarraconense, que atiende también al estado actual de la investigación del mundo rural en época romana (Revilla, González y Prevosti, 2008 y 2011) o el proyecto Ager Tarraconensis, del que se derivan importantes obras colectivas sobre el poblamiento rural en torno a la capital tarraconense (Prevosti y Guitart 2010, Prevosti, López y Guitart 2010). Son destacables asimismo algunos trabajos desarrollados sobre la zona central y septentrional de la costa catala- 
na en los que se aportan datos de identificación arqueológica de los sitios (Plana y Revilla 2007).

En el cuadrante NO, hay que señalar las investigaciones generales llevadas a cabo sobre Gallaecia por F. Pérez Losada, en las que plantea el estudio y caracterización del poblamiento disperso y agrupado en este ámbito geográfico y sus diferentes manifestaciones (Pérez Losada 1996; 2002). Otras vías de análisis sobre el ámbito galaico emprendidas más recientemente profundizan en los procesos de transformación del ámbito rural tras el abandono de los castros (SánchezPardo 2010), en tanto que de otros proyectos interesados en el conocimiento del mundo rural romano sólo se han dado a conocer unas primeras aproximaciones (Rodríguez Resino 2007; Carlsson-Brandt 2011). En la Asturia Cismontana poseen un peso indudable las investigaciones llevadas a cabo por el grupo Estructura social y territorio. Arqueología del Paisaje del Instituto de Historia del CSIC, dirigido por F. J. Sánchez-Palencia. En el marco de sus numerosos trabajos sobre los paisajes mineros del NO destacamos algunos que abordan específicamente el estudio del poblamiento rural en este ámbito (Orejas 1996; Sánchez Palencia 2000; Sánchez-Palencia, Orejas y Sastre 2002; Orejas 2005; Orejas y Ruiz del Árbol 2010, entre otros). En el territorio astur transmontano cabe citar las recientes aportaciones realizadas por $\mathrm{C}$. Fernández Ochoa y F. Gil (2011) en las que se revisan algunas atribuciones de yacimientos a categorías concretas de poblamiento rural y los estudios territoriales llevados a cabo por O. Requejo (2014) en la cuenca del río Nora. Más hacia el Oriente, en el sur de Cantabria y en las provincias de Palencia y Burgos hay que referir la obra de J. García Sánchez (2010).

Para el Alto Ebro pueden mencionarse las prospecciones realizadas en el entorno de Los Bañales (Andreu, Lasuén y Jordán 2009) y, sin salir de Aragón, el estudio sobre el somontano pirenaico, en el territorio de la ciudad de Barbotum (Barbastro) (Chasseigne 2001-2002) o la aproximación al poblamiento romano de Los Monegros (Giral 2004).

En Extremadura, los primeros trabajos sobre este asunto se enmarcaron en los parámetros metodológicos de la Arqueología Espacial (Cerrillo y Fernández Corrales 1980; Fernández Corrales 1983 y 1988; entre otros), aunque algo después se realizaron también aportaciones interesadas en el estudio del ámbito rural lusitano desde perspectivas espaciales, morfológicas, filológicas o materiales, como las recogidas en sendos volúmenes editados por la Casa de Velázquez (Gorges y Salinas de Frías 1994; Gorges y Rodríguez Martín 1999). Más recientemente, este tema constituye el objeto de interés de un grupo de investigadores del Instituto de Arqueología de Mérida (CSIC), que tiene ya en su haber una serie de notables resultados (Mayoral y Celestino 2010; Mayoral et alii 2013), entre los que se encuentran también aportaciones metodológicas (Mayoral, Cerrillo Cuenca y Celestino 2009; Mayoral y Sevillano 2013). Asimismo, en el ámbito lusitano han de destacarse los trabajos emprendidos en territorio salmantino por el citado grupo Estructura social y territorio. Arqueología del Paisaje (Sánchez-Palencia y Ruiz del Árbol 2000).

En tierras portuguesas son dignas de mención las aportaciones de M. Martins sobre el territorio bracarense (Martins, Sande Lemos y Pérez Losada 2005; Martins y Carvalho 2010, entre otras), de C. Lopes (2003) sobre el área de Beja, de M. J. de Almeida (2000) sobre el concelho de Elvas y de F. Teichner y Th. Schierl (2010) en el sur de Lusitania.

En Andalucía, el desarrollo de los estudios sobre las formas del paisaje rural romano tiene su arranque en las conocidas prospecciones desarrolladas por M. Ponsich (1974; 1979 y 1987) en el alto y medio Guadalquivir, a las que han sucedido otras actuaciones protagonizadas por miembros de la Universidad de Sevilla (García Vargas, Oria y Camacho 2002). De igual modo, hemos de hacer mención a las investigaciones llevadas a cabo por la Universidad de Córdoba en la Subbética cordobesa (Vaquerizo, Murillo y Quesada 1991; 1992; Carrillo 1991) y a las realizadas en Huelva sobre los territorios mineros (Pérez Macías et alii 2009; Pérez Macías y Delgado 2012) o en el ámbito de la Tierra Llana (Campos y Gómez Toscano, 2001). En el caso malagueño cabe citar las interpretaciones sobre el área de Antequera (Prieto, Cortadella y Olesti 2001; Corrales 2007), y en Jaén, los estudios territoriales concernientes al ámbito minero del sur de Sierra Morena (Gutiérrez Soler y Casas 2010; Gutiérrez Soler 2012).

En el SE, reiteramos la mención a los trabajos sobre diferentes comarcas murcianas (Orejas y Ramallo 2005; Noguera 1995; 2010) y, ya en el área de Levante, hemos de referir a la síntesis realizada por Frías (2011) acerca del entorno rural de varias civitates alicantinas y, sobre todo, a las investigaciones emprendidas por miembros de la Universidad de Alicante sobre el ámbito rural de la Contestania ibérica y romana, que se materializan en algunos análisis interpretativos y en propuestas metodológicas para el registro de datos sobre el terreno (Grau et alii 2012; Grau y Molina 2013). En la zona valenciana hay que reseñar los estudios sobre la ribera del Júcar (Pérez Ballester y Arasa 2010).

Por último, el interior peninsular cuenta también con algunos estudios prospectivos sobre el territorio rural romano en ambas mesetas. En la zona sur podrían mencionarse trabajos en el área de Toledo (Urbina 1999; Rodríguez y Barrio 2003) y Cuenca (Macías 2008). En cuanto a Ciudad Real, podemos incluir dentro de este elenco las investigaciones que dos de nosotras estamos llevando a cabo en el territorium de Sisapo y que han comenzado a bosquejar la imagen de un poblamiento rural asociado a las explotaciones 
mineras en la vertiente norte de Sierra Morena (Zarzalejos et alii 2012 a y b). En la Meseta Norte referiremos las aportaciones de C. García Merino (2007) sobre el territorio rural en el valle del Duero en época bajoimperial y de F. López Ambite (2009) sobre el NE de la provincia de Segovia. Cerca de la frontera hispanoportuguesa, las tierras zamoranas están siendo objeto de una activa investigación relacionada con las explotaciones auríferas de la zona minera de Pino del Oro (Sánchez-Palencia et alii 2010).

Sin haber agotado en modo alguno el repertorio de aportaciones que fundamentan su base interpretativa en trabajos de prospección, otro gran conjunto de estudios sobre el ámbito rural romano se orientan al análisis de las estructuras agrarias y han bebido metodológicamente de la línea de investigación arqueomorfológica desarrollada desde hace casi tres décadas por la escuela francesa encabezada por G. Chouquer, M. Clavel-Lévêque y F. Favory (Chouquer et alii 1987; Chouquer y Favory 1991 y 2001; Chouquer 1996, entre otros muchos). Los estudios arqueomorfológicos en nuestro país se han encauzado al conocimiento de la estructuración de los espacios agrarios a lo largo del tiempo. Aunque este enfoque se aparta ligeramente del asunto que constituye el objeto central de nuestro trabajo, dado que no suele comportar categorizaciones terminológicas de los asentamientos de tipo rural, no podemos dejar de aludir a él porque constituye una base fundamental para el conocimiento del campo hispanorromano.

Se dispone de un compendio de obras de carácter general que abordan los problemas de método y concepto que muestran mayor injerencia a la hora de investigar las huellas de las estructuras agrarias del pasado (Ariño et alii 1994; González Villaescusa 1996; Ariño y Diaz 1999; Ariño 2003; Palet 2005 a, entre otros), así como de trabajos monográficos que ofrecen una visión de conjunto sobre el estado de la cuestión aplicado a Hispania y que contienen referencias a casos concretos (González Villaescusa 2002; Ariño, Gurt y Palet 2004). Dentro de estas obras de enfoque general no puede dejar de mencionarse alguna llamada al orden que reflexiona sobre los presupuestos teóricos de partida y la materialidad de los resultados conseguidos, al tiempo que revisa de manera crítica algunas investigaciones sobre catastros en diferentes ámbitos de la geografía hispana (González Villaescusa 2006).

En el marco de estas líneas de trabajo se han sucedido importantes avances sobre el conocimiento de los paisajes centuriados en el territorium de diversas civitates hispanas. En el NE, la capital tarraconense ha sido objeto de intensos análisis en la última década (Palet 2003; 2005 b; Arrayás 2005; Palet et alii 2010; Palet y Orengo 2010, entre otros), así como también la colonia Barcino (Palet 1997; Olesti 2008; Palet, Fiz y Orengo 2009, entre otros) y otros espacios de la actual
Cataluña, como el Maresme (Olesti 1995) o el Vallés (Flórez 2011; Flórez y Palet 2012; Oller 2013).

En el valle medio del Ebro cabe reseñar los estudios realizados en su día por E. Ariño $(1986 ; 1990)$ y, ya en otros ámbitos geográficos, aparte de algunos ensayos que han suscitado discusión, como los realizados sobre la colonia Astigi (Sáez, Ordóñez y GarcíaDils 2002), hay que referir a las investigaciones realizadas sobre los catastros de Ilici (Gurt, Lanuza y Palet 1996; Mayer y Olesti 2001; González Villaescusa 2007), Augusta Emerita (Ariño y Gurt 1994; Ariño et alii 1994) y un trabajo ya citado que recoge varias investigaciones sobre las tierras valencianas (González Villaescusa 2002). En territorio portugués pueden mencionarse, a título de ejemplo, las propuestas de identificación de centuriaciones en torno a Ebora (Plana 2002) y Bracara Augusta (Carvalho 2008).

Se encuentran también en proceso de estudio otros modelos de paisajes no centuriados que comienzan a producir resultados de gran interés para el conocimiento de las estructuras agrarias en amplias zonas de la geografía hispana no sometidas a la formulación del ager divisus et asignatus. Así, por citar algunos de los casos más intensamente tratados en los últimos años, podemos aludir a las investigaciones sobre algunas zonas pirenaicas como las del entorno de Iulia Livica (Llivia) (Olesti, Mercadal y Valiente 2005), Andorra y la Sierra del Cadí (Orengo 2010; Palet et alii 2013, entre otras). También en los casos de Helmantica (Salamanca) o Palantia (Palencia) parece indudable su adscripción en la modalidad de ager per extremitatem mensura comprehensus (Front. De agrorum qualitate, 7-9), lo que implicaría de facto un cierto mantenimiento de los sistemas productivos prerromanos tras la integración del territorio en torno a la nueva civitas (Orejas y Sastre 1999; 2003), situación que, según las citadas autoras, habría que extender a todo el Noroeste.

\section{A MODO DE REFLEXIÓN FINAL}

A través de la documentación textual y arqueológica se observa que el paisaje rural romano se caracterizó por una notable diversificación. Hoy en día se constata la existencia tanto de formas agrupadas de ocupación más o menos asimilables a la amplia terminología contenida en los textos escritos y epigráficos (vici, conciliabula, fora, mansiones, castella, pagi) como la presencia, dentro del ámbito rural, de núcleos dispersos cuya nomenclatura solo se refleja ocasionalmente en la documentación textual (villae, casae, aedificia, tuguria), sin olvidar la existencia de simples edificaciones aisladas vinculadas a la red viaria (mutationes).

Parece indudable que las villae de considerables dimensiones han mantenido un especial protagonismo en la historiografía general del mundo romano debido al volumen y eminencia de sus estructuras y a la tradi- 
cional dedicación de los investigadores al estudio de este tipo de residencias. Sin embargo, cada vez son más numerosos los estudios enfocados al conocimiento arqueológico intensivo de determinados territorios o micro-regiones, que ponen de relieve la existencia de formas de ocupación de distinto rango que no siempre permiten otorgar carta de naturaleza a la diversidad, a veces un tanto confusa, transmitida por la documentación textual. Por otra parte, el reconocimiento en el paisaje de las huellas dejadas por estos establecimientos de menor categoría se empieza a valorar de forma más ajustada mediante investigaciones amparadas en nuevas técnicas y métodos, cuya aplicación y eficacia era impensable hace tan sólo un par de décadas. No obstante, todavía debemos hacer una llamada de atención sobre este particular puesto que, al cotejar algunos estudios de fecha muy reciente, un número no despreciable de autores siguen apostando por identificar como villae algunos establecimientos rurales de difícil atribución para los que no se dispone de una información arqueológica contrastada. Es obvio que la interpretación de los datos de superficie supone un problema importante a la hora de identificar categorías o formas de ocupación, pero no lo es menos que esta es la vía más directa, y por el momento creemos que única, de aproximación al conocimiento de los paisajes antiguos. Del rápido recorrido bibliográfico que hemos realizado más arriba, podría deducirse que existe una cierta base informativa, al menos nominal, sobre las formas de ocupación rural en diferentes ámbitos del suelo hispano. Pero cuando se amplía el zoom se perciben notables diferencias regionales y también importantes desigualdades metodológicas que atañen no sólo a la elección del protocolo de trabajos a aplicar, sino a los planteamientos teóricos que subyacen a éste. Aunque pueda parecer una obviedad, es preciso insistir en la necesidad de adoptar unos patrones procedimentales genéricos en la toma de datos que permita homogeneizar las bases informativas, de manera semejante a lo que sucede en una excavación estratigráfica, donde nadie cuestiona desde hace décadas cómo debe hacerse el registro. El siguiente paso implica al procesado e interpretación de los datos de cara a definir jerarquías y modelos de establecimientos. La clasificación funcional o tipológica de lugares o yacimientos rurales suele apoyarse en una serie de criterios o ítems, como el tamaño del yacimiento o la extensión de los restos, el tipo y cantidad de material arqueológico, la posición del lugar en relación con determinados tipos de recursos, etc. Para lograr resultados equiparables sería conveniente que los criterios a considerar fueran homologables. Obviamente, esto no significa que su aplicación deba ser necesariamente homogénea a todos los territorios, ya que las formas de ocupación rural manifiestan una cierta diversidad regional que impide generalizaciones, sino que lo que planteamos es la conveniencia de emplear unos mismos criterios y que sean los umbrales de categorización los que marquen las diferencias en cada ámbito territorial. Aún con todo, e intentando no caer en un excepticismo postprocesual a ultranza, opinamos que la correlación entre las realidades identificadas en los trabajos de campo y las figuras recogidas por las fuentes escritas y la epigrafía seguirá planteando problemas si se trabaja únicamente con inferencias derivadas de trabajos superficiales. Un complemento muy útil para los trabajos de registro en superficie es la aplicación de técnicas de prospección geofísica, seleccionando las que mejor se adapten a las condiciones del área a explorar o, mejor aún, una combinación de diversas técnicas sobre un mismo lugar. Sin embargo, para contrastar las hipótesis funcionales nos parece imprescindible combinar el programa de prospecciones intensivas con la excavación puntual en yacimientos catalogados dentro de categorías diferenciadas. Sólo estos trabajos pueden aportar el armazón temporal que permitirá valorar los procesos de cambio en las estructuras agrarias. En este sentido, nos parece fuera de duda el interés que suscita el análisis del tránsito entre la época prerromana y la implantación romana y entre la Antigüedad Tardía y la Alta Edad Media, ya que se introducen dos momentos de transición que hacen posible observar los cambios o transformaciones experimentados por las estructuras rurales o, en otros casos, las líneas de continuidad.

Por lo que respecta a las villae, más allá de los sectores residenciales dotados de formas arquitectónicas monumentales y de amplios programas decorativos, se impone acometer una investigación mucho más precisa sobre este tipo de establecimientos. A grandes rasgos podemos apuntar algunas cuestiones pendientes como el problema del origen e implantación de las villae en territorio peninsular, objeto de un activo debate en algunas regiones como el NE (Olesti, 1997 y 2010) pero prácticamente ausente en otros estudios peninsulares.

Otro tanto se puede decir acerca de la definición de este tipo de establecimientos a lo largo del periodo altoimperial. Se podría afirmar que las villae altoimperiales son todavía las grandes desconocidas debido a diversos motivos, entre otros, la exigüa conservación de los restos emergentes. Si bien es cierto que muchos de los testimonios de estos asentamientos han sido parcial o totalmente destruídos por los nuevos edificios suntuarios no lo es menos que nuestro desconocimiento procede, en bastantes ocasiones, de una práctica de excavación poco rigurosa. En algunos yacimientos reexcavados recientemente como Almenara (Valladolid) o Veranes (Gijón, Asturias), se han puesto de relieve la valiosa entidad de ciertas evidencias correspondientes a la villa de cronología altoimperial que antecedió a la construcción de estos complejos fundiarios tardios. Por el contrario, resulta difícil de aceptar la pérdida irreparable de estructuras altoimperiales en el caso de otras villae que muestran numero- 
sos materiales de esta etapa cronológica en posición secundaria. Otra cuestión sin resolver es el problema de la absorción de las pequeñas granjas o villae altoimperiales que debieron de incorporarse a las grandes propiedades tardorromanas, asunto éste difícil de calibrar sin un ambicioso plan de excavaciones a mayor escala que los efectuados hasta el momento en nuestro país.

En cuanto a la configuración de las grandes villae tardías, ya hemos señalado líneas arriba que se dispone de una información apreciable sobre la pars urbana mientras aún nos hallamos muy lejos de poder definir numerosos aspectos de estas propiedades en sus zonas rústicas. De no menor importancia es el estudio de los fundi que aún sigue pendiente, bien sea en relación con su origen o con su evolución puesto que es la propiedad de la tierra y su explotación lo que constituye la verdadera razón de ser de estos establecimeintos residenciales rurales. Sin embargo, no resulta fácil obtener una imagen detallada del tejido ocupacional del dominio de una villa y de la organización de su explotación económica, a cuyo territorio se vincularon, indudablemente, modelos ocupacionales de diferente tipo en consonancia con las necesidades productivas de las zonas beneficiadas en cada fundus .

Por último, aunque lentamente, observamos un cierto progreso en el problema de la continuidad y/o transformación de las villae hispanas en la tardía antigüedad (López Quiroga y Rodriguez Martín 20002001; Arce y Ripoll 2001; Chavarría 2005). Procesos de abandono y reocupación del espacio motivados por cambios de tipo político, religioso o socio-económoco, es decir, la acción de nuevos propietarios o el desplazamiento del centro de poder de la antigua villa a otros núcleos de nueva creación, nos ofrecen un panorama cada vez más novedoso a partir del momento en el que las grandes villae habían ido perdiendo progresivamente su carácter originario.

Si lugar a dudas, una asignatura pendiente en el panorama peninsular es el estudio de los establecimientos agrupados de caracter rurales o aglomeraciones secundarias que también algunos denominan como vici. Son muy exiguos los casos conocidos a través de datos arqueológicos fehacientes. Otro tanto se podría decir de los asentamientos vinculados a la red viaria cuya investigación apenas ha comenzado en nuestro país.

El Apéndice terminológico recoge otras muchas denominaciones que sería prolijo comentar aquí y cuya referencia se analiza en cada casuística. El lector observará que, en muchos casos, no ha sido posible, al menos de momento, ofrecer ejemplos de las formas ocupacionales rurales de Hispania que se correspondan con una realidad arqueológica contrastada.

\section{APÉNDICE}

Denominaciones genéricas de núcleos relacionados con la ocupación y explotación del territorio.

Villa, -ae: Este concepto comprende instalaciones rurales de diversa índole, incluyendo desde construcciones muy modestas, tipo granja (Varro. rust. 3, 2, 3), hasta grandes centros de explotación rural ${ }^{15}$, con partes diferenciadas en zona residencial y rústica (Varro. rust. $3,2,9)$ a la que se añade la pars fructuaria dedicada al almacenaje y procesado de alimentos (Colum. 1, 6, 1). También puede referirse a lugares placenteros de ocio ${ }^{16}$ o incluso a residencias imperiales. Aunque en el mundo clásico, la diferenciación entre granja y casa rural no es tan clara ${ }^{17}$, la bibliografía actual germana e italiana tiende a diferenciar los centros de explotación rurales como villae rusticae, de las casas de campo residenciales y lujosas definidas como villae urbanae. Este concepto presenta un componente territorial, de modo que las construcciones se asocian a la existencia de un fundus ${ }^{18}$ o con una gran propiedad (Varro. rust. 3, 2,5). El término territorial villa corresponde al fundus y mantiene una estrecha asociación con el pagus, de modo que a veces villa aparece como sinónimo de pagus (Serv. Georg. 2, 382), o bien su construcción define el territorio ${ }^{19}$. Respecto a la dimensión arquitectónica de las villae hispanorromanas, son numerosos los estudios realizados como se ha visto en páginas anteriores.

Villula, -ae: dominio agrícola de escasa extensión (Catulo, Carmina, 4, 21; Cic. ad Atticus, 6, 16), dotado de un edificio modesto, similar a la villa que menciona Varrón (rust. 3, 2, 3), pero con una connotación peyorativa. Puede referirse a residencias de pequeñas familias campesinas, con vocación agropecuaria que se

15 Ferdière trató de identificar la villa romana desde un punto de vista arquitectónico, definiéndola como "une exploitation agricole comportant une partie résidentielle plus o moins importante, et construite 'en dur' a la manière romaine" (1988 (1): 158). Esta propuesta ha sido discutida por otros autores (Leveau et alii, 1999).

16 Varro. rust. 3, 2, 3. Gros (2001) aborda la cuestión planteando su función como una "structure de domination et de profit" así como una "structure de plaisance"; por su parte, Lafon (2001) ha estudiado en detalle las villae maritimae y

"lacustres" construidas por la aristocracia romana entre finales de la República y comienzos del Imperio para el descanso y el ocio placentero.

17 Vitruv. De architect. 6, 6, 6; Varro. rust. 3, 5; Colum. 1, 46.

18 Colum. 1, 4, 8; Plin. NH. 18, 6, 1; Dig. 1, 16, 211; CIL X, 444.

19 Plaut. rud. 33-34; Ps. Quint. Decl. Mai. XIII, 2. Vid. Letta 2005: 89-90. 
construyen con materiales sencillos. Horacio evoca con este término una casa agradable retirada en el campo (Hor. Serm. 2, 3, 10). Durante el periodo tardoantiguo, se asimila a este término la palabra uillare, que se refiere a una pequeña población rural con un territorio limitado (Martínez Melón 2006: 126). En el ámbito hispano se confirma la permanencia del término villulam en época tardoantigua, pues aparece mencionado más veces que la palabra villa en los concilios de Toledo (Mellado 1990; Isla 2001).

Vicus, - $i$ : hábitat rural agrupado (Festo, De Verborum Significatu, 70), dependiente de una ciudad, que presenta una cierta autonomía con responsabilidades políticas, religiosas, administrativas y fiscales, de modo que cuenta con administradores entre los que destacan los magistri, junto con los aediles, quaestores, curatores, actores y decemlecti (Chevallier 1986: 5). Además de los vici rurales, existe una acepción distinta relativa al poblamiento civil asentado junto a los campamentos militares que también recibe el nombre de vici, además de canabae, términos relativos a aglomeraciones con jurisdicción dependiente del ejército, que no trataremos en este trabajo ${ }^{20}$.

Desde el punto de vista arquitectónico, presentan un plan urbanístico y coherente (Tácito, Opera Minora, 16, 2). Así pues, tanto por sus monumentos como por su funcionalidad, podría asemejarse a un barrio urbano, que es el otro significado que le otorga Festo al término vicus (Letta 2005). Según San Isidoro de Sevilla, el espacio del vicus está bien organizado con vías (Etym. 15, 2, 11) y desprovisto de murallas (Etim. 15, 2, 6, 7) y de la dignitas propia de una ciudad, siendo definida como "una simple reunión de personas que por su pequeñez, está adscrita a ciudades mayores" (Etim. 15, 2, 11).

A partir de la identificación de los vici realizada por Grenier (1934: 695), éstos cumplen funciones religiosas y económicas, son centros administrativos, termales, establecimientos forestales con fana, y en ocasiones, también ofrecen servicios relacionados con las etapas en las vías de comunicación, a los que la bibliografía francesa denomina vici routiers y que por el

20 Existe todavía una notable confusión entre los términos

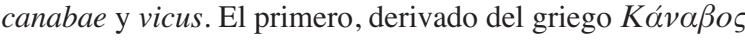
(maderamen, armazón) se suele interpretar como campamento de barracones, cabañas, tenderetes, aludiendo sin duda a su fisonomía originaria. Este término fue principalmente usado en relación con los campamentos legionarios. Pero conocemos también aglomeraciones civiles establecidas junto a campamentos legionarios que reciben en las fuentes literarias o en la epigrafía la denominación de vicus (Mogontiacum, Argentorate, Vindonissa), por lo que dicha distinción debe ser matizada. Según Bérard, vicus sería la denominación más común, aplicable a aglomeraciones civiles nacidas al socaire tanto de campamentos legionarios como de fuertes auxiliares. El término canabae no es un término empleado en todos los casos (Vitinghoff 1970 y 1971 ; momento en la historiografía española se han identificado en contadas ocasiones como, por ejemplo, en el caso de Lucus Asturum (entornos de Lugo de Llanera, Asturias) (Fernández Ochoa et alii 2005, 134) o el de Corao también en tierras asturianas (Requejo y Gutiérrez 2009, 177). La ley agraria 643/111 (Corp. inser. lat. 1, n.200, v. 11, 12) nos advierte de la presencia de vici viasiorum y viasii vicani, es decir, una categoría de vici presentes en Italia que corresponden a grupos de población sometidos, en concepto de tributos especiales, al mantenimiento de las vías principales que conectaban Roma con sus colonias.

En Hispania, las fuentes escritas nos informan sobre la existencia de un vicus Italicensis situado en la Baetica (Corp. inser. lat. 2, 1119 y 1, 546 y 149) y se conservan numerosas inscripciones que mencionan la presencia de vicani (CIL II2/7, 272; CIL II2/7, 273), como los vicani Vadiniensis (AE 1928, 170), Vagornicenses (AE 1982, 567), Atucausenses (CIL II 6287), Cabr(icenses) (HEp 4, 1994, 1016), Venienses (Curado 1979: 145-148), vicani ilex[...] (AE 2001, 1209), goaboaic(enses) (AE 1985, 525), Camaloc [...] (CIL II 170), Tongobricenses (CIL II, 743), Roud( ensibus?) (HEPol 2911), Arcobrigenses (HEp 5, 1995, 226), Mace [- - - Jenses (HEp 5, 1995, 228), Munenses (ERCMCC 119), Ocelonenses (HEp 11, 2001, 673). La epigrafía también notifica la presencia de vicus, como el vicus Baedorus (CIL II 365; Curchin 1985, $\mathrm{n}^{\circ} 3$, 330). Por la lex Metallis de Vipasca se conoce la existencia de un vicus no dependiente de un oppidum o de una ciudad y controlado directamente por un procurator metalli (Lazzarini 2001).

Locus, - $i$ : este término se refiere tanto a una zona geográfica o fiscal (Juan de Biclaro, Chronicon, a.570; XIII Concilio de Toledo, canon VI), como a un hábitat disperso, cuya importancia en época bajoimperial está asociada al aumento considerable del control territorial del castellum (Castellanos y Martin Viso 2005: 9-14). Este término también puede referirse a hábitats estacionales o temporales ligados a prácticas como la trashumancia (Martínez Melón 2006: 125). El vocablo se conoce a través de citas epigráficas en Italia y en el sur

Sommer 1984: 3-4; Poulter 1989). En ciertas regiones como la Dacia, la documentación de este tipo de asentamientos es fundamentalmente epigráfica (Ciobanu 1998) y no parece verificarse su uso hasta mediados del siglo II d. C. (Bérard 1993). Para el caso hispano, carecemos de inscripciones que mencionen canabae o vici militares, sin embargo contamos con una interesante referencia en la carta 67 de San Cipriano dirigida a las comunidades cristianas de LeónAstorga y Mérida, a un posible vicus, del que incluso conocemos su nombre -Ad Legionem VII Geminam- (Teja 1990 y 2005; Loewinsohn 1999: 11-12; Fernández Ochoa y Morillo 2005: 164). Recientemente se ha podido vincular con el asentamiento civil situado junto a la margen izquierda del río Torío, a poco más de $2 \mathrm{~km}$ del extremo meridional del campamento de León (v. Morillo y Salido 2014). 
de la Gallia (Leveau 1994). En Hispania no se ha podido atribuir esta denominación a ninguna estructura rural conocida (Pérez Losada 2020: 37).

Forum, - $a$ : centros cívicos situados en un espacio rural disperso, dotados de funciones administrativas, políticas y comerciales, que se fueron creando por iniciativa de Roma en la fase de expansión y posterior organización del territorio. Es una realidad rural que se documenta en una fase muy antigua (tardorrepublicana) que desaparece en el siglo I d.C. y se limita a Italia y algunas provincias occidentales, como Cerdeña, Gallia e Hispania. El surgimiento de la mayor parte de estos centros rurales coincide con la expansión de las vías del Imperio debido a su función comercial. Es un modelo de asentamiento que permitía a las autoridades romanas organizar grandes territorios sin la necesidad de implantar una colonia, especialmente en zonas de montaña donde el modelo de colonia era menos viable (Crespo Cabillo 2009). La denominación de alguno de estos fora alude a los nombres de las vías a las que están asociados, por ejemplo, el Forum Apii, al paso de la vía Apia o Forum Flaminii, junto a la vía Flaminia; también se refieren, aunque en menor medida, a nombres étnicos, como es el caso del Forum Germanorum o el Forum Gallorum entre otros. En Hispania, esta denominación también se encuentra en la estación itineraria Forum Gallorum (It. Antonino 425,7; Rav. IV, 43) de localización desconocida en las ruta hacia el Pirineo desde Caesaraugusta a Beneharno.

Son comunes los fora que llevan el apelativo de los emperadores que los promovieron, como los alpinos (Forum Claudii Vallensium y Forum Claudii Ceutronum) o los sardos (Forum Traiani y Forum Augusti o Augustae). En Hispania, se conocen varias menciones a fora en ámbito rurales en el cuadrante noroeste peninsular (Ptol. 2, 6, 43/ 37/ 42/48). En otras zonas, los fora se encarnaron en fórmulas urbanas como el Forum Iulium Iliturgi (Mengibar, Jaén) ${ }^{21}$, Libisosa Forum Augustum (Lezuza, Albacete) (Ptol. II/6/58) (Poveda Navarro 2002; Uroz Rodriguez 2012).

Conciliabulum, - $a$ : etimológicamente se refiere a un lugar de reunión donde se celebra un concilium o asamblea de ciudadanos con una finalidad administrativa o política. Al igual que en los fora, no parece que hubiera en los conciliabula magistrados que se encargaran del censo, de modo que esta función sería realizada por censores enviados directamente desde Roma como medida extraordinaria en momentos puntuales de necesidad (Liv. 25, 22, 4; 43, 14, 7). Según Picard (1970), los conciliabula constituyen centros cívicos que sirven de referencia y punto central de una población rural dispersa. La arqueología ha olvidado completamente la existencia de estos espacios de los que, sin embargo, las fuentes escritas nos ofrecen una imagen viva ${ }^{22}$.

Denominaciones de núcleos relacionados con la ocupación y explotación del territorio con connotaciones defensivas.

Oppidum, - $a$ : este concepto adquirió una nueva dimensión con la reorganización administrativa que sucedió a la conquista de las provincias occidentales. Se puede entender como un hábitat agrupado o lugar central de un territorio o como el principal asentamiento de una civitas o pagus ${ }^{23}$, en el que se hallan edificios, construcciones y rasgos espaciales propios de una ciudad, con murallas (Polibio 3, 90, 8; Lucano, 4, 224), o desprovistos de estos elementos defensivos ${ }^{24}$. En ocasiones, aparece referido como sinónimo de civi$\operatorname{tas}^{25}$. En época altoimperial pasó a usarse de forma genérica para referirse a colonias, municipios y prefecturas (Plin. NH. 3, 3, 7), por oposición a otras formas de ocupación como vici, castella y a otros núcleos de hábitat que no habían sido fundados mediante rito inaugural alguno (Turpin 1999: 288-293; Fumadó 2013). También se refiere a comunidades no incorporadas, es decir, peregrinas, como es el caso del oppidum Baelo $(3,7)$, oppida Carbula, Detumo $(3,10)$. En las fuentes se define la existencia de oppida civium Romanorum (coloniae y municipia civium Romanorum), oppida Latinorum, oppida libera, foederata y stipendiaria. En el caso hispano, aparece mencionado en el Bronce de Lascuta, asociado al territorio (agrum oppidumque) (D’Ors 1953: 349-352); también Livio $(43,8)$ hace mención a la existencia de oppida en Hispania (sibi oppidum in quo habitarent daretur). En época posterior, la muralla pasa a definir el oppidum. Así, por ejemplo, San Isidoro de Sevilla diferencia el oppidum de otro tipo de asentamientos, como los vici, castella y pagi por su magnitud y sus murallas (Etim. 15, 2, 6, 7).

Castellum, - $a$ : el término se refiere a una entidad de poblamiento (agrupado o disperso) que articula el espacio rural en el marco de la civitas (Orejas y Ruíz del Árbol 2010: 1112). Se diferencia del vicus por su posición geográfica, pues generalmente se encuentran
21 Iliturgi aparece con la denominación forum en Plinio, N.H. III, 10 y en It. Antonino, 403,2 (Arteaga y Blech, 1985; Jiménez Cobo, 2000).

22 Tabula Heraclensis; la Lex repetund. (Corp. I 583) 31 o la Lex Rubr. (Corp I 592- CIL XI, n. 1146) II 3.

23 Lex Acilia del 123 a.C., CIL I2, 583,31; Lex Agraria del 111 a.C., CIL I2, 585,5.
24 Dion. Hal. Ant. Rom. 1, 9, 2. Tito Livio menciona explícitamente que hay oppida fortificados (Liv. 28, 15, 14-15; 35, 22,5 ) y otros sin defensas (Liv. 22, 11, 4).

25 Cic. Resp. 1, 26, 41; Varro. LL. 5, 143; Liv. 42, 20, 3; 42, 36,1 . 
situados a cierta altura o en un lugar privilegiado desde el punto de vista estratégico y por la existencia de fortificaciones que protegen el recinto (AE 1966, 594). El castellum cuenta administrativamente, al igual que el vicus, con magistrados como los curiales (AE 1904, 145). El uso alternativo de los términos castellum y castrum en la Galia e Hispania, bien conocidos en la epigrafía hispana por la existencia de la $C$ invertida $^{26}$ para referirse a estos asentamientos, permite suponer el uso indiferenciado de ambos para aludir a realidades parecidas $^{27}$. La aportación más reciente y clarificadora sobre los castella se debe a Orejas y Ruíz del Árbol (2010) a partir del análisis de los textos escritos y epigráficos y de las aportaciones de la arqueología no sólo en el ámbito del NO o de la península ibérica sino también de otras provincias del Imperio. Estas autoras plantean una revisión crítica acerca de lo inapropiado de identificar castros y castella y explicitan el papel fundamental que los castella jugaron en la articulación de las nuevas relaciones sociales plasmadas territorialmente frente a los que sostienen su papel como reflejo de la perduración de cieros elementos del mundo prerromano como se ha afirmado habitualmente (Orejas y Ruíz del Árbol 2010: 1113).

En época bajoimperial estas aglomeraciones secundarias aumentan su importancia con un mayor control administrativo en la organización del territorio frente a la civitas. La problemática del término castella en las fuentes tardías ha sido abordada, entre otros autores, por Arce en relación con la posible identificación de villa con castellum (Arce 2006: 10-11).

Centenarium, $-a$ : construcciones fortificadas destinadas a la protección y seguridad de los habitantes de un territorio que pudieron ser edificadas por privados o pudieron ser puestos oficiales, generalmente situados en posiciones estratégicas a lo largo de las vías militares. En origen debieron ser puestos fortificados situados en el limes o zona de frontera, y quizás estaban planteados y organizados para una centuria de tropas regulares, de donde procedería su denominación (Smith 1971: 308-309). Su origen se sitúa en la franja del limes norteafricano en el siglo IV d.C. (cf. Leschi 1941: 171). La epigrafía del limes de la Tripolitania nos informa sobre otras variantes como centenari, centeinari y centenare (Elmayer 1985: 79) y de la existencia de construcciones privadas (casas y estableci-

26 Sobre esta cuestión, intensamente debatida en la historiografía de los últimos treinta años, véanse diversas interpretaciones en Pereira Menaut 1982; Le Roux y Tranoy 1983; Ferreira da Silva 1986 ; Alarcão 1988 y 2003; González y Santos 1994; Brañas 1995; López Barja 1999; Sastre 2001; García Quintela 2002.

27 AE 1961, 96; Veg. epitome rei militaris, 3; Casiod. variae, 1, 17; 3, 48; 8, 25; Julián de Toledo, Historia Wambae, 3, 59-60), e incluso castellum se emplea como mientos rurales fortificados) que cumplían una función similar a la de los puestos militares (Elmayer 1985: 82). Desde el punto de vista constructivo, se definen por ser construcciones fortificadas de planta cuadrada o cuadrangular, dotadas de torres en las cuatro esquinas del recinto y puertas bien defendidas situadas en la parte central de cada uno de los cuatro tramos del lienzo murario (Leschi 1941: fig. 2).

Burgus,- $i$ emplazamiento fortificado que cumple la función de mantener la vigilancia en los caminos para la seguridad de los viajeros (CIL VIII, 2495; CIL VIII, 2494) y en zonas fronterizas. Se han podido reconocer arqueológicamente en la frontera renana y danubiana en época tardoimperial (Johnson 1983: 270-279).

Quadriburgium, - $a$ : emplazamientos fortificados de pequeño tamaño (menos de 1 ha) y planta rectangular o cuadrangular dotados de cuatro torres en las esquinas. Se han reconocido a nivel arqueológico en zonas fronterizas del norte de África (Mattingly 1995; Arce 2010) y en el limes renano-danubiano (Johnson 1983; Redeé 1995; Brulet 2006: 56). En los años setenta se excavó, en Formentera, el yacimiento de Can Bai que ha sido interpretado como una fortificación de control marítimo de este mismo tipo (González Villaescusa y Dies 1993).

Turris, -es: edificio fortificado que cumple la función de mantener la vigilancia en emplazamientos concretos, como en las fronteras ${ }^{28} \mathrm{o}$ en los caminos para la seguridad de los viajeros. Se suelen situar en puntos elevados, junto a ríos o manantiales, con un efectivo control sobre el territorio circundante. Generalmente se visualizan unos a otros, estableciéndose así un eficaz sistema de alerta temprana. Constructivamente, se trata de estructuras muy simples, que suele consistir en una sola torre o atalaya cuadrangular, rectangular o trapezoidal, aunque en ocasiones se presentan además anillos de fortificación rodeando esa torre principal ${ }^{29}$. $\mathrm{Su}$ aparejo se define como ciclópeo con sillares, dispuestos en hiladas más o menos regulares, poco desbastados y asentados en seco o trabados con barro, siendo frecuente la presencia de ripios y lajas de piedra entre ellos para asegurar la estabilidad de los muros (Gómez y Pedregosa 2013: 268).

diminutivo de castrum (Mauro Honorato, Commentarii in Vergilii, VI, 4, 69.

28 Se han podido reconocer desde el punto de vista arqueológico, al igual que los burgi, en la frontera renana y danubiana en época tardoimperial (Brulet, 1993,138: 56).

29 Los diversos tipos de turres documentados hasta el momento ha generado un debate historiográfico en torno a su definición, de modo que son interpretadas de forma diversa, como torres-recinto, recintos fortificados y casas-fuerte. 
Para el caso hispano, Plinio nos informa sobre la presencia de las Turres Hannibalis, es decir, un sistema de atalayas costeras con hogueras de aviso para ahuyentar a los piratas (Plin. NH, 2, 181) o torres edificadas en Hispania y en África, situadas en las cumbres de los cerros (Plin. NH, 35, 48, 169). También Tito Livio indica que existían turres utilizadas contra los bandidos (Livio 22, 19, 6). La epigrafía además nos informa sobre la existencia de la Turris Lascutana (Alcalá de los Gazules) que, por el decreto de Emilio Paulo del 189 a. C., quedó sometida a servidumbre del oppidum de Hasta (Jerez de la Frontera), formando parte de su territorio (ager) (García Moreno 1986). Un estudio reciente ha permitido identificar diferentes turres de época romana en la provincia de Granada (Gómez y Pedregosa 2013).

Denominaciones de núcleos relacionados con vías, lugares de estacionamiento o parada

Mansio, -nis: establecimiento viario destinado al hospedaje, alojamiento y posada de los viajeros durante una noche o un breve periodo de tiempo ${ }^{30}$. Etimológicamente el término procede de la palabra manere que significa "detenerse" (Corsi 2000: 40). Algunas inscripciones conservadas, como el epígrafe de Burdur (AE 1976, 653), nos informan sobre el funcionamiento de algunas mansiones, indicando que el alojamiento es gratuito solamente para el emperador y su séquito o para magistrados que están cumpliendo servicio en provincias (Di Paola 1999: 26-31), de lo que también las fuentes escritas nos informan ${ }^{31}$. Entre éstos, se encuentran los curiales que realizan operaciones relacionadas con el correo oficial (Plut. Galb. 8). Las fuentes jurídicas emplean indistintamente los términos mansio y mutatio para referirse a establecimientos oficiales relacionados con el cursus publicus $^{32}$

Desde el punto de vista arquitectónico, son similares a las residencias urbanas, dotadas en algunas ocasiones con establos (stabula) (Ap. Met. 10, 1; Lact. de Mort. Pers. 24, 6-7), cuyo forraje era surtido por los oficiales asentados en las ciudades ( Cod.

30 Cic. ad Att. 2, 16, 4, 3; 8, 15, 2, 8; 9, 5, 1, 5-6; 9, 10, 8, $10 ; 11,6,6,2 ; 16,1,3,2 ;$ ad Quint $3,1,9,4 ; 18,4 ;$ ad Fam. 4, 4, 5, 6; Peregrinatio Egeriae, fuentes n ${ }^{\circ} 29,36$, 37, 71 y 72; Paneg. 6, 16, 1; Lact. de Mort. Pers. 45, 6; Symm. Epist. 1, 20, 3; 2, 27; 7, 32, 1; 8, 58, 1; CIL III, 7000; CIL V, 2108

31 Plin. NH. 12, 65; Apul. Met. 1, 17, 8; Ambr. in Psalm 118, 5, 2, 2-3; 5, 3, 3-5; 5, 5, 1; Ambr. de Obitu Valent. 24

32 Cod. Theod. 1, 16, 12; 7, 10, 1; 8, 5, 23; 8, 5, 35; 8, 10, 2; $11,1,9 ; 11,1,21 ; 12,1,21 ; 12,1,119 ; 12,6,21 ;$ Cod. Just. 10, 26, 2; 12, 35, 11; Dig. 50, 4, 18, 10; Lex Burg. Lib. Const. 38,3 y 5-6.

33 Se han documentado en asentamientos civiles próximos a campamentos militares como en los vici de Saalburg
Theod. 8, 5, 60; 11, 1,9) e incluso, en época adrianea, las mansiones de Britannia eran financiadas por el fiscus (Black 1995: 9). En algunas ciudades y vici militares, se han puesto al descubierto también edificios de grandes dimensiones que pudieron cumplir la función de mansiones (Wacher 1974; Drury 1982). A nivel general, presentan planta rectangular o cuadrangular con diversas estancias que rodean un patio central $^{33}$.

Mutatio, -nis: establecimiento viario donde era posible cambiar los caballos y que cuenta con instalaciones muy sencillas. Etimológicamente procede de la palabra permutare (cambiar) (Corsi 2000: 40). Se emplea el término tanto para referirse al propio acto de cambio de los animales (Amm. 14, 11, 19; 21, 9, 4) como para las estaciones de parada y cambio (Cassiod. Var. 1, 29, 2; 4, 47, 6; 8, 32, 1; Casiod. Hist. Eccl. 6, 45, 2). Como ya se ha indicado, las fuentes jurídicas emplean, sin distinción, el término mutatio y mansio para referirse a paradas oficiales relacionadas con el cursus publicus (Cod. Theod. 11, 1, 9; 8, 5, 34; $8,5,36 ; 12,50,15 ; 12,50,17-18)$. Se conservan inscripciones que nos informan sobre las órdenes imperiales de reducir la distancia entre una mutatio y otra con el fin de hacer más fluido el viaje y ofrecer mejores servicios en el transcurso del mismo (CIL V, $8658,8987)$ e igualmente se legisla sobre el uso de los lugares de pastoreo y parada en estos emplazamientos (CIL IX, 2826, 4).

Desde el punto de vista arqueológico, las mutationes han permanecido fuera de la atención de los especialistas, dada su simplicidad y los escasos restos materiales conservados. Algunas mutationes pudieron encontrarse en el interior de las ciudades como la mutatio Valentia mencionada en el Itinerario Burdigalense localizada en la via Traiana en Salento (Boersma 1995) y otras cerca de grandes núcleos urbanos como Augusta Raurica en Suiza dotada de un gran complejo comercial, un espacio de alojamiento, granero y acueducto (Bender 1975: 25-26). Los ejemplos hispanos ya han sido comentados (vid. supra).

(Moneta 2010: 89-92), Caer Gai (Burnham et alii 2007: 248, fig. 6), Cefn Caer (Hopewell et alii 2005: 232), Chester (Mason 1987: 149-150, fig. 4), Old Carlisle (Higham y Jones 1975), Carlisle (Caruana 1976), Vindonissa (Drack y Fellman 1988: 539-544), Schlögen/Ioviacum (Bender y Moosbauer 2003: 224-225), Regensburg (Faber 1994: 5154), Caerleon (Wright 1956: 119, fig. 20) y quizás Mirebeau (Goguey 2008: 238). Asímismo se asignan esta categoría a otros emplazamientos como Godmanchester (Green 1975: 199, fig. 11), Lower Wanborough (Phillips y Walters 1977: 226, fig. 2), Silchester (Boon 1974), Heddernheim (Gündel 1911, fig. 7) y Corbridge (Salway 1965: 51, fig. 6). 
Statio, -nis: lugar de encuentro y de negocios situados en los caminos ${ }^{34}$, que, en ocasiones, corresponde a un lugar fortificado ${ }^{35}$. Es el término más frecuente en las fuentes escritas y se mantiene hasta el último cuarto del siglo IV d.C. ${ }^{36}$. En ocasiones, cumplen la función de aduana (AE 1981, 724). Se conservan testimonios que nos informan sobre la corrupción de ciertas personas que cobran en exceso por los carros que transitan ${ }^{37}$. En Hispania, por el momento son escasos los restos interpretados como stationes $\mathrm{y}$, algunas identificadas, ofrecen dudas como la supuesta statio dotada de turris localizada en el Tossal de Cal Montblanc (Albesa, La Noguera, Lleida) (vid. supra).

Deversorium/Diversorium, - $a$ : instalación de carácter privado que las familias más acomodadas mandaban construir para su estacionamiento o lugar de parada a lo largo de los caminos que conducían a sus lejanas propiedades ${ }^{38}$. Para Arce (2006: 11) esta especie de albergues pueden confundirse con las stationes que jalonaban las vías ya que servían como refugio y lugar de descanso nocturno. Su identificación arqueológica resulta muy problemática.

Catabulum, - $a$ : oficina central del cursus, en ocasiones del correo oficial de los gobernadores (AE 1976, 502). Apenas contamos con información sobre estos puestos; la única referencia conservada se refiere a un catabulum urbano situado en Roma (Corsi 2000: 55).

Stabulum, -a: término empleado desde el siglo I d.C. para referirse a un lugar de parada y pernoctación dotado de instalaciones para el resguardo de los animales (Kleberg 1957: 18-19), como nos informan tanto las fuentes textuales ${ }^{39}$ como las epigráficas (AE 1959, 179; CIL VI, 1,1774). El establo se diferencia de la simple taberna situada en los caminos (Varro. ling. lat. $5,15)$. Fueron empleados sus servicios incluso por los emperadores (S.H.A. Sept. Sev. 1, 10) y para evitar peligros en momentos determinados (Cypr. Epist. 68, $3)$. Algunas fuentes nos informan sobre el cobro de los servicios en función de las mercancías y el equipaje acarreado por los comerciantes (Dig. 17, 2, 52, 15). Los restos arqueológicos del stabulum Hermetis loca-

34 Suet. Nero. 37, 2; Plin. Epist. 2, 9, 5; Juv. 11, 2-5; Corsi 2000: 40

35 Cic. ad Att., 6, 9, 5, 7; ad Fam. 12, 15, 2, 13.

36 Ambr. in Psalm. 118, 5, 3, 3-5; Amm. 27, 4, 8; 28, 6, 27.

37 Cod. Theod. 6, 29, 5) o los abusos de los oficiales (Cod. Theod. 6, 29, 6; 8, 5, 36; 8, 5, 65 .

38 Varro. rust. 1, 2, 23; Cic. ad. Fam. 6, 19, 1; Hor. Epist. 1, 15, 10; Suet. Vitell. 7, 6; Cod. Theod. 1, 16, 12.

39 Digesto, 4, 9, 5; Suet. Vitell. 7, 6; Apul. Met. 1, 4; 1, 15; 1, 21; 9, 4; 10, 1; Aug. Serm. 177, 2; 178, 8, 9; 200, 1, 1 .

40 Cic. de Div., 1, 57; Sen. de Benef. 1, 14, 1; Hor. Sat. 1, 5, 1-6; Plin. Epist. 6, 19, 4; 8, 8, 6; Hier. Epist. 77, 10. Vid lizados en Pompeya nos indican la existencia de stabula en las zonas extramurarias de las ciudades, junto a los accesos y puertas de la ciudad, constituidos por patios que permiten estacionar los carros y establos para el descanso y vigilancia de los caballos durante la noche (Kleberg 1957: 43; Casson 1974: 205 y ss). En Italia se han documentado también stabula situados en los caminos como en la parada de Casalbordino (Corsi 2000: 176-177) y también en otras regiones como Egipto, concretamente en el Heita y Bad el Mukheinig (Reddé y Golvin 1987). Para Hispania cerecemos de referencias.

Hospitium, - a: lugar de acogida de los hospites recibidos o amigos ofrecidos entre familias de gran poder adquisitivo que presumen de no tener que compartir espacio en los hospedajes humildes ${ }^{40}$. En algunos textos aparece referido a estación destinada a la asistencia médica de los enfermos (S.H.A. Hadr. 10, 6) y como lugares de hospedaje de militares (S.H.A. Aurel. 7, 8).

Stativa, -ae: lugar de parada destinado al abastecimiento en el ámbito militar ${ }^{41} \mathrm{y}$ al descanso en el ámbito civil que se pueden hallar en cualquier emplazamiento (Levi 1967: 110; Corsi 2000: 31 y 41), pero que generalmente se circunscriben a lugares poblados y selectos, para el confort y la seguridad del viajero ${ }^{42}$. Se conservan testimonios jurídicos que nos informan de la regulación de los suministros concedidos a los viajeros en las stativae ${ }^{43}$.

Palatium, - $a$ : en época imperial, además de poseer otros significados, se refiere a las estaciones de parada más lujosas y mejor dotadas del cursus publicus, para hospedar al propio emperador o a alguno de sus emisarios ${ }^{44}$. En algunas fuentes escritas, el término palatium aparece mencionado como lugar de alojamiento de los emperadores en contraposición a los praetoria que se definen como lugar de parada de los viajeros más comunes ${ }^{45}$. Se encontraban tanto en las cercanías de las ciudades atravesadas por las vías más importantes (Cod. Theod. 7, 10,1) como en emplazamientos alejados de los itinerarios (Cod. Theod. 7, 10, 2).

\section{Corsi 2000: 41.}

41 Fronto, ad. M. Caes. 3, 4, 47-48; S.H.A. Sev. Alex. 45, 2; Veg. epit. 3, 8, 1 y ss.

42 S.H.A. Sev. Alex. 47, 1; Peregrinatio Egeriae 18, 1; 19, 3; 23,$2 ; 23,6$.

43 Cod. Theod. 8, 6, 2; Cod. Just. 12, 51, 1.

44 Cod. Theod. 7, 10, 1-2; Dig. L, 4, 18, 10. Vid Uggeri 1995: 137-140.

45 Cod. Theod. 7, 10, 2. En algunos documentos epigráficos, praetorium aparece mencionado como lugares de parada en vías militares (CIL III, 6123; AE 1912, 193; Ivanov 1973: 209). 


\section{BIBLIOGRAFÍA}

Abascal Palazón, J. M., Cebrián, R., Ronda, A. y Sala, F. (2007): Baños de la reina (Calpe, Alicante) un vicus romano a los pies del Peñón de Ifach. Alicante.

Ackerman, J. S., (1990): The villa: from and ideology of country houses. Washington.

Alarcão, J. (1988): Roman Portugal, Warminster.

Alarcão, J. (2003): “A organização social dos povos do noroeste e Norte da Paninsula Ibérica as épocas prerromana y romana", Conimbriga 42, 5-115.

Almeida de, M. J. (2000): Ocupaçâo rural romana no actual concelho de Elvas. Coimbra.

Alonso, A., Cerrillo Martín de Cáceres, E. y Fernández Corrales, J. M. (1992-93): “Tres ejemplos de poblamiento rural romano en torno a ciudades de la Vía de la Plata: Augusta Emerita, Norba Caesarina y Capara", Studia Historica. Historia Antigua 10$11,67-88$.

Andreu, J., Lasuén, M. y Jordán, Á. A. (2009): “El poblamiento rural en el territorium de la ciuitas vascona de Los Bañales en época romana", Trabajo de Arqueología Navarra, 21, 121-160.

Aounallah, S. (2010): Pagus, castellum et civitas. Étude d'epigraphie et d'histoire sur le village et la cité en Afrique romaine, Scripta Antiqua, 23. Bordeaux.

Arasa i Gil, F. (2013): “L'Hostalot (Vilanova d'Alcolea, el Baix Maestrat). Excavacions a la "mansio Ildum" de la via Augusta. El complex arquitectònic de l'horreum", Quaderns de prehistòria i arqueologia de Castelló 31, 163-202.

Arce, I. (2010): “Limes Arabicus: Qasr Hallabat, Qasr Bashir and Deir El Khaf. Building techiques, architectural typology and change of use of three quadriburgia from the Limes Arabicus. Interpretation and significance", en H. Dessales, S. Camporeale y A. Pizzo (eds.): Arqueología de la construcción II. Los procesos constructivos en el mundo romano: Italia y provincias orientales, Madrid, 455-484.

Arce, J. (1990): "El cursus publicus en la Hispania tradorromana", La red viaria en la Hispania Romana. Zarazgoza, 35-40.

Arce, J. (2006): "Villae en el paisaje rural de Hispania romana" en A. Chavarría, J. Arce y G. P. Brogiolo (eds.): Villas tardoantiguas en el Mediterráneo occidental, Anejos de Archivo Español de Arqueología, 39. Madrid.

Arce, J. y Ripoll, G. (2001): “Transformación y final de la villae en occidente (siglos IV-VII). Problemas y perspectivas", Arqueología y territorio medieval $8,21-54$.

Ariño, E. (1986): Centuriaciones romana en el valle medio del Ebro, provincia de La Rioja. Logroño.
Ariño, E. (1990): Catastros romanos en el convento jurídico caesaraugustano, la región aragonesa. Zaragoza

Ariño, E. (2003): “Tipos de campo, modelos de hábitat. Problemas metodológicos e interpretativos de los catastros romanos en Hispania", en J. Guitart, J. M. Palet y M. Prevosti (eds.): Territoris antics a la Mediterrània i a la Cossetania oriental. Barcelona, 97-116.

Ariño, E. y Diaz, P. (1999): "La economía agraria de la Hispania romana: colonización y territor io", Stvdia historica, Historia antigua 17, 153-192.

Ariño, E. y Gurt, J. M. (1994): “Catastros romanos en el entorno de Augusta Emerita. Fuentes literarias y documentación arqueológica”, en J. G. Gorges y M. Salinas (eds.): Les campagnes de Lusitanie romaine. Madrid, 45-66.

Ariño, E., Gurt, J. M. y Palet, J. M. (2000-2001): "La inscripción catastral de Ilici. Ensayos de interpretación", Pyrenae, 31-32, 223-226.

Ariño, E., Gurt, J. M. y Palet, J. M. (2004): El pasado presente: arqueología de los paisajes en la Hispania romana. Salamanca.

Ariño, E., Gurt, J. M., Lanuza, A. de y Palet, J. M. (1994): "El estudio de los catastros rurales: una interpretación estratigráfica del paisaje", Zephyrvs, XLVII, 189-217.

Arrayás Morales, I. (2005): Morfología histórica del territorio de Tárraco (Siglos III a.C.-I a.C.), Instrumenta, 19, Barcelona.

Arteaga, O. y Blech, M.: (1985): "Exploraciones en el Cerro de Maquiz", Madrider Mitteilungen, 26, 177-190.

Aupert, P., Fincker, M. y Tassaux, F., (1998): "Agglomérations secondaires de l'Aquitaine atlantique", en P. Gros (dir.): Villes et Campagnes en Gaule romaine, Comité des travaux historiques et scientifiques. $120^{e}$ Congrès national des Sociétés historiques et scientifiques (Aix-en-Provence, 1995). Paris, 45-69.

Baldini, I. (2001): La domus tardoantica.Forme e representación dello spacio domestico nelle cittá del Mediterráneo. Bologna.

Banaji, J. (2001): Agrarian Change in Late Antiquity: Gold, Labour and Aristocratic Dominance. Oxford.

Barker, G. y Lloyd, J. (eds.) (1991): Roman Landscapes: Archaeological Survey in the Mediterranean Region. London.

Bellet, M.-E. (1999): Agglomérations secondaires antiques en Région Centre. Tours.

Bénard, J. (1994): Les agglomérations antiques de Côte-d'Or, Serie Archéologie 39, Annales littéraires de l'Université de Besançon 522. Paris. 
Bender, H. y G. Moosbauer. 2003. Das römische Donaukastell Schlögen in Oberösterreich. Die Funde aus den Grabungen 1957-1959, 1984 und die Altfunde. Passauer Universitätsschriften zur Archäologie 8, Leidorf.

Bender, H. (1975): Römische Strassen und Strassenstationem, Stuttgart.

Bentmann, R. y Muller, M. (1992): The Villa as Hegemonic Architecture. New Jersey/ London.

Bérard, F. (1993): "Vikani, kanabenses, consistenses: remarques sur l'organisation des agglomerations militaires romaines", en A. Calbi, A. Donati y G. Poma (eds.): L'epigrafia del villaggio. Epigrafia e Antichita 12. Faenza, 61-90.

Bernal Casasola, D. (2011): "Piscicultura y ostricultura en Baetica. Nuevos tiempos, nuevas costumbres", en D. Bernal (ed.): Pescar con Arte Fenicios y romanos en el origen de los aparejos andaluces Baetica. Cádiz, 137-160.

Bernal, D., Roldán, L., Blánquez, J., Prados, F. y Díaz, J. J. (2004), "Villa Victoria y el barrio alfarero de Carteia en el s. I d.C. Avance de la excavación del año 2003", en D. Bernal y L. Lagóstena (eds.), Talleres alfareros y producciones cerámicas en la Bética romana (ss. II a.C.-VII d.C.), Actas del Congreso Internacional Figlinae Baeticae, British Archaeological Reports, I.S. 1266, 457-472.

Bertoncello, F. (2002): "Villa/vicus: de la forme de l'habitat aux réseaux de peuplement" Revue archéologique de Narbonnaise, Tome 35, 39-58

Best, R. H. (1973): The urban countryside: the landuse structure of small towns and villages in England and Wales. London.

Black, E. W. (1987): The Roman villas of south-east England, BAR British series 171. Oxford.

Black, E. W. (1995): Cursus publicus: the infrastructures of government in Roman Britain. Oxford.

Blánquez, J. Bernal, D., Roldán, L., Díaz, J. J., y Prados, F. (2005), "Primeros datos acerca de las posibles instalaciones portuarias de Carteia y de la producción tardorromana de púrpura. Excavación de urgencia en el Callejón del Moro", Caetaria, 45, 315-317.

Bodel, J. (1997): "Monumental villas and villa monuments", JRA 10, 5-35.

Boersma, J. (1995): Mutatio Valentia. The Late Roman Baths at Valesio, Salento, Amsterdam.

Bowes, K. (2010): Houses and Society in the Later Roman Empire. Duckworth.

Brandt, R y Slofatra, J. (1983): Roman and Native in the Low Countries: Spheres of Interaction. Oxford.

Branigan, K. y Miles, D. (eds.) (1989): The Economics of Romano-British Villas, Sheffield.

Brañas, R. (1995): Indixenas y romanos na Galicia céltica. Santiago de Compostela.
Brulet, R. (1993): "Les fortifications militaires du BasEmpire en Gaule Septentrionale » en L'Armée romaine et les barbares. Memoire AFAM. Toulouse, 135-148.

Bugalhão, J. (1998): “O povoamento rural romano no Alentejo: contribuição da arqueología preventiva", Revista portuguesa de Arqueologia 1 (2), 123-136.

Burnham, B. C., Hunter, F., Booth, P. Worrell, S., Tomlin, R. S. O. \& Hassall, M. W. C. (2007): "Roman Britain in 2006", Britannia 38, 241-366.

Burnham, B. y Wacher, J. (1990): The Small Towns of Roman Britain. Berkeley.

Busquets, F., Moreno, A. y Revilla, V. (2013): "Hábitat, sistemas agrarios y organización del territorio en el litoral central de la Laietània", Paysages ruraux et territoires dans les cités de l'Occident romain. Gallia et Hispania, Actes du colloque international AGER IX, Barcelona, 239-249.

Camacho Macías, A. (1998): El libro de la vida de los Santos Padres de Mérida. Mérida.

Campos Carrasco, J. M. y Gómez Toscano, F. (2001): La Tierra Llana de Huelva: arqueología y evolución del paisaje. Sevilla.

Carandini, A. (1985): Settefinestre: una villa schiavistica nell'Etruria romana. Modena.

Carandini, A. y Cambi, F. (2002): Paesaggi d'Etruria. Roma.

Carlsson-Brandt, E. (2011a): "El poblamiento rural en la Galicia romana. Un ejemplo: las villae. Metodología y problemática en su estudio", Estrat Critic 5, vol.I, 156-167.

Carlsson-Brandt, E. (20111b): "El poblamiento rural romano en Galicia. Resultados preliminares", Férvedes, 7, 207-213.

Carrillo Pinés, J. R. (1991): "El poblamiento romano en la Subbética cordobesa", Anales de arqueología cordobesa, 2, 225-252.

Caruana, I. (1996): “A Forum or Mansio in Carlisle?", Britannia 27, 345-353.

Carvalho, H. P. (2008): “Organization cadastrale autour de Bracara Augusta (Braga, Portugal)", Dialogues d'Histoire Ancienne, 34/1, 155-160.

Casas i Genover, J. (1995): El món rural d'època romana a Catalunya, Centre d'Investigacions Arqueològiques de Girona 15. Girona.

Casson, L. (1974): Travel in the ancient World, London.

Castellanos, S. y Martin Viso, I. (2005): "The local articulation in the north of the Iberian Peninsula", Early Medieval Europe 13, Oxford, 1-42.

Cerrillo Martín de Cáceres, E. y Fernández Corrales, J. M. (1980): "Contribución al estudio del asentamiento romano en Extremadura. Análisis espacial aplicado al S de Trujillo", Norba, 1, 157-177. 
Chasseigne, L. (2001-2002): "Prospection dans le piémont pyrénéen : le nord du somontano de Barbastro (Huesca) à l'époque romaine", Salduie, II, 177-194.

Chavarría Arnau, A. (1999): "Novedades bibliográficas sobre villae en Hispania durante la Antigüedas Tardía (1990-1999”, Bulletin de l'Association pour l'Antiquité Tardive 8, 57-67.

Chavarría Arnau, A. (2005): El final de las "villae" en "Hispania" (siglos IV-VIII), Bibliothèque de l'Antiquité Tardive 7. Turnhout.

Chavarría, A., Arce, J. y Brogiolo, G. P. (eds.) (2006): Villas tardoantiguas en el Mediterráneo occidental. Anejos de Archivo Español de Arqueología 39. Madrid.

Chevalier, R. (ed.) (1976): Le vicus gallo-romain. Paris.

Chevallier, R. (1986): "Les sources de la recherche", Le vicus gallo-romain, Paris, $2-8$.

Chouquer, G. (1996) (dir.) : Les Formes du paysage. Tome-2 Archéologie des parcellaires. Paris.

Chouquer, G. y Favory, F. (1991): Les paysages de l'Antiquité. Terres et cadastres de l'Occident romain (Ive. S. avanta J.C./IIIe s. après J.C.). Paris.

Chouquer, G. y Favory, F. (2001) : L'arpentage romain.Histoire des textes, droit, techniques. Paris.

Chouquer, G., Clavel-Levêque, M., Favory, F. y Vallat, J.-P. (1987): Structures agraires en Italie centromeridionale, Cadastres et paysages ruraux. Collection de l'École Française de Rome. Roma.

Ciobanu, R. (1998): "Canabae, vici et castella en Dacie romaine", Caesarodunum, Bulletin de l'Institut d'études latines et $d u$ Centre de recherches A. Piganiol 32, 349-363.

Collart, J.-L. y Bayard, D. (1996): "De la ferme indigène à la villa romaine", Revue archéologique de Picardie 11, 5-8.

Colleoni, F., Petit-Aupert, C. y Sillières, P. (2013): "Paysages ruraux et formes de mise en valeur des campagnes en Aquitaine méridionale (cités d'Auch, d'Eauze et de Lectoure)", Paysages ruraux et territoires dans les cités de l'Occident romain. Gallia et Hispania, Actes du colloque international AGER IX, Barcelona, 213-222.

Corrales, P. (2007): "La organización del campo malacitano durante la época romana", Mainake XXIX, 249-271.

Corsi, C. (2000): Le strutture di servizio del Cursus Publicus in Italia: ricerche topografiche ed evidenze archeologiche, Oxford.

Cotton, M. A. (1979): The Late Republican Villa at Posto, Francolise, London.
Crespo Cabillo, C. (2009): "Los “fora” de la época imperial: los ejemplos alpinos y sardos", Veleia 26, 287-295.

Curado, F. (1979): "Epigrafia das Beiras", Conimbriga $18,145-148$.

Curchin, L. A. (1985): "Vicus and pagi in Roman Spain”, REA LXXXVII, 3-4, 327-343.

D’ Ors, A. (1953): Epigrafía jurídica de la España romana. Madrid.

Dark, K. y Dark, P. (1997): The Landscape of Roman Britain Phoenix Mill. Gloucestershire.

De la Bédoyère, G. (1993): Book of roman villas and the countryside. London.

Di Paola, L. (1999): Viaggi, trasporti e istituzioni. Studi sul cursus publicus. Messina.

Dilke, O. A. W. (1971): The Roman Land Surveyors. New York.

Drack, W. y Fellman, R. (1988): Die Römer in der Schweiz, Stuttgart.

Drury, P. J. (1982): "Form, function, and the interpretation of the excavated plans of some large secular Romano-British buildings", P. J. Drury (ed.): Structural reconstruction: approaches to the interpretation of the excavated remains of buildings, 289-304.

Duprey, P. (1994): The Villas of Pliny from Antiquity to Posterity. Chicago.

Durliat, J. (1990): Les finances publiques de Diocletien aux Carolingiens (284-889), Beihefte der Francia, 21, Sigmaringen.

Dyson, S. (2003): The Roman countryside. London.

Dyson, S. L. (1983): The Roman Villas of Buccino. Oxford.

Elmayer, A. F. (1985): "The Centenaria of Tripolitania", Libyan Studies 16, 77-84.

Etienne, R. (1990): Les villas romaines de Sao Cucufate. Paris.

Faber, A. (1994): Das römische Auxiliarkastell und der Vicus von Regensburg- Kumpfmühl, Münchner Beiträge zur Vor- und Frühgeschichte Bd. 49, München.

Favory, F. y Fiches, J.-L. (dirs.) (1994) : Les campagnes de la France méditerranéenne dans l'Antiquiteé et le haut Moyen Âge. Approaches microrégionales, Documents d'Archéologie Française 42. Paris.

Ferdière, A. (1988): Les campagnes en Gaule romaine. Paris.

Fernández Castro, M. C. (1982): Villas romanas en España. Madrid.

Fernández Corrales, J.M. (1983): “El asentamiento rural romano en torno a los cursos alto y medio del Salor: su marco geográfico y distribución", Norba 4, 207-222. 
Fernández Corrales, J.M. (1988): El asentamiento romano en Extremadura y su análisis espacial. Cáceres

Fernández Ochoa, C. y Morillo, A. (2005): La arqueología hispanorromana a fines del siglo XX. Bibliografía temática y balance historiográfico. Madrid.

Fernández Ochoa, C. García Diaz, P. y Zarzalejos, M. (2005): Excavaciones arqueológicas en Lugo de Llanera (Asturias). Memoria de las Campañas de 1991 a 1995. Oviedo.

Fernández Ochoa, C. García-Entero, V y Gil Sendino, F. (eds.) (2008): Las villae tardorromanas en el occidente del Imperio, arquitectura y función. IV Coloquio Internacional de Arqueología en Gijón. Gijón.

Fernández Ochoa, C. y Gil Sendino, F. (2011): "Villae romanas en Asturias", en V. Revilla, J.R. González y J. Guitart (eds.): Simposi sobre Les vil.les romanes a la Tarraconense. Implantació, evolució i trasnformació. Estat actual de la investigació del món rural en época romana, Vol. II, Barcelona, 49-72.

Fernández Ochoa, C., Gil Sendino, F. y Orejas Saco Del Valle, A. (2004): "La villa romana de Veranes. El complejo rural tardorromano y propuesta de estudio del territorio", Archivo Español de Arqueología 77 (189-190) pp. 197-220.

Fernández Ochoa, C., Gil Sendino, F., Salido Dominguez, J. y Zarzalejos Prieto, J. (2012): El horreum de la villa romana de Veranes (Gijón, Asturias). Primer testimonio material de los hórreos de Asturias. Madrid.

Ferreira da Silva, A. C. (1986): A cultura castreja de Portugal, Pagos de Ferreira.

Fiches, J.-L., (dir.) (2002): Les agglomérations galloromaines en Languedoc-Roussillon, I. Monographies d'Archéologie Méditerranéenne 13. Lattes, 138-147.

Fiches, J.-L., Plana-Mallart R., y Revilla V. (eds.) (2013): Paysages ruraux et territoires dans les cités de l'occident romain. Gallia et Hispanial Paisajes rurales y territorios en las ciudades del occidente romano.Gallia e Hispania. Actes du colloque international Ager IX. Barcelona.

Flórez, M. (2011): Dinámica del poblament i estructuració del territori a la Laietània interior. Estudi del Vallès Oriental de l'Època Ibèrica fins a l'alta Edat Mitjana, Universidad Autónoma de Barcelona. Tesis Doctoral. Bellaterra.

Flórez, M. y Palet, J. M. (2012): “Análisis arqueomorfológico y dinámica territorial en el Vallés Oriental (Barcelona) de la Protohistoria (s.VI-Va.C.) a la alta Edad Media (s. IX-X)", Archivo Español de Arqueología 85, 167-192.

Fornell Muñoz, A. (2005): Las villae romanas en la Andalucía Mediterránea y del Estrecho. Jaén.
Francovich, R. (2003): Villa to village: the transformation of the roman countryside in Italy, c.4001000. London.

Frazer, A. (ed.) (1998): The Roman villa "Villa urbana": first Williams Symposium on Classical Architecture held at the University of Pennsylvania, Philadelphia, april 21-22, 1990, University Museum monograph 101, Symposium series 9. Philadelphia.

Frías Castillejo, C. (2011): El poblamiento rural de Dianium, Lucentum, Ilici y la ciudad romana de la Vija Joiosa (siglos II a.C.-VII d.C. Bases para su estudio. Alicante.

Fumadó Ortega, I. (2013): “Oppidum. Reflexiones acerca de los usos antiguos y modernos de un término urbano", SPAL 22, 173-184.

García Entero, V. (2002): Los "balnea" domésticos ámbito rural y urbano- en la Hispania romana, Anejos de Archivo Español de Arqueología 37. Madrid.

García Entero, V. (2005-2006): "Las transformaciones de los balnea rurales domésticos durante la antigüedad tardía en "Hispania" (ss. IV-VI)", Cuadernos de prehistoria y arqueología 31-32, 6182.

García Entero, V. (2006): "Los balnea de las villae tardoantiguas en Hispania", en A. Chavarría, J. Arce y G. P. Brogiolo (eds.): Villas tardoantiguas en el Mediterráneo Occidental, 97-112

García Guinea, M. A. (dir.) (2000): La villa romana de Quintanilla de la Cueza (Palencia). Memoria de las excavaciones 1970-1981. Salamanca.

García Moreno, L. A. (1986): "Sobre el decreto de Paulo Emilio y la "Turris Lascutana" (CIL XII, 614)", Reunión sobre epigrafía hispánica de época republicana. Zaragoza, 195-218.

García Quintela, M.V. (2002): La organización sociopolítica de los populi del Noroeste de la penísula Ibérica. Un estudio de antropología política histórica comparada. Santiago de Compostela.

García Sánchez, J. (2010): "El poblamiento y la explotación del paisaje en la Meseta Norte entre la Edad del Hierro y la época romana altoimperial. Una aproximación a través de la arqueología espacial", Zephyrvs LXIV, 81-96.

García Valdeiras, M. (2001): "O Forum Limicorum", Minius 9, 39-50.

García Valdeiras, M. (2004-2005): "Escavasions arqueoloxicas en Xinzo de Limia (Xullo 2003Xullo 2004)", Lethes 6, 199-209.

García Vargas, E., Oria Segura, M. y Camacho Moreno, M. (2002): "El poblamiento romano en la campiña sevillana: el término municipal de Marchena", Spal 11, 311-340. 
Garmy, P. (2002): "Villa-vicus une question d'espace?, Revue archéologique de Narbonnaise 35, 27-38.

Garraffo, S. (1988): La villa romana del Casale de Piazza Armerina. Atti della IV Riuone Scientifica della Scuola di Perfezionamento in Archeologia Classica dell'Università di Catania (Piazza Armerina, 28 settembre-1 ottobre 1983), Cronache di archeologia 23. Catania.

Giral Royo, F. (2004): "Introducción al poblamiento de época romana en Los Monegros", Revista d'Arqueologia de Ponent 14, 223-235).

Goguey, R. (2008): "Légionnaires romains chez les lingons: la VIIIème Avgvsta à Mirebeau (Côted'Or)", Revue Archéologique de l'Est 57, 227-251.

Gómez Comino, D. y Pedregosa Megías, R. J. (2013): "Aproximación a las turres de época romana en la provincia de Granada", Revista del Centro de Estudios Históricos de Granada y su Reino 25, 265-288.

González Villaescusa y R., Díes, E. (1991-1992), "Evolución de la ocupación del suelo de Formentera Epocas púnica y romana", Cuadernos de Prehistoria y Arqueología Castellonenses 15, 335-373.

González Villaescusa, R (2007): “Ce que la morphologie peut apporter à la connaissance de la centuriation d’Ilici (Elche, Espagne)", Agri centuriati 4, 29-42.

González Villaescusa, R. (1996): “Arqueología del paisaje e historia agraria: algunas cuestiones de método", Revista d'Historia Medieval, 7, 223-242.

González Villaescusa, R. (2002): Las formas de los paisajes mediterraneos, (Ensayos sobre las formas, funciones y epistemologia parcelarias: estudios comparativos en medios mediterráneos entre la antigüedad y época moderna). Jaén.

González Villaescusa, R. (2006): “¿Qué arqueología del paisaje?", Catastros, hábitats y vía romana, programa INTERREG III B de la Unión Europea: Las Vías Romanas en el Mediterráneo. Valencia, 215-246.

González, M.C. y Santos, J. (eds.) (1994): Revisiones de Historia Antigua I: las estructuras sociales indígenas en el Norte de la Península Ibérica, Anejos de Veleia. Vitoria.

Gorges, J. G. (1979): Les villas hispano-romaines. Burdeos.

Gorges, J.G. y Rodríguez Martín, F.G. (2000): “Voies romaines, propriétés et propriétaires à l'ouest de Mérida: problèmes d' occupation du sol en moyenne vallée du Guadiana sous le Haut-Empire" en Gorges, J.G. y Nogales, T., Sociedad y cultura en Lusitania romana. Mérida, 101-153.

Gorges, J.G. y Rodríguez Martín, G. (eds.) (1999): Économie et territoire en Lusitanie romaine. Madrid.
Gorges, J.G. y Salinas de Frías, M. (eds.) (1994): Les campagnes de Lusitanie romaine. Madrid.

Grau, I. y Molina, J. (2013): "Diversite territoriale et modeles de exploitation aux paysages ruraux du Sud de la Tarraconense (ss. II av.-II apr.)", en J.L., Fiches, R. Plana-Mallart y V. Revilla Calvo (eds.): Paysages ruraux et territoires dans les cités de l'occident romain. Gallia et Hispania, Actes du colloque International Ager IX. Barcelona, 53-60.

Grau, I., Carreras, C., Molina, J., de Soto, P. y Segura, J. M. (2012): "Propuestas metodológicas para el estudio del paisaje rural antiguo en el área central de la Contestania", Zephyrvs LXX, 131-149.

Grenier A. (1934): Manuel d'Archéologie gallo-romaine, $t$. II - L'Archéologie du sol. Paris.

Gros, P. (2006): L'Architecture romaine. II. Maisons, palais, villas et tombeaux. Paris.

Gurt, J. M., Lanuza, A. de y Palet, J. M. (1996): "Revisión del catastro romano de Ilici (Elche)", Pyrenae 27, 215-226.

Gutiérrez Soler, L. M. (2012): “Arqueología del paisaje minero en el sector oriental de Sierra Morena", en A. Orejas y Ch. Rico (eds.): Minería y metalurgia antiguas: visiones y revisiones: homenaje a Claude Domergue. Madrid, 105-128.

Gutiérrez Soler, L. M. y Casas, A. (2010): "Poblamiento y antiguas labores mineras de época romana en la provincia de Jaén", Minería antigua en Sierra Morena. Jaén, 105-156.

Hauschild, T.y Arbeiter, A. (1993): La villa romana de Centcelles. Barcelona.

Hidalgo, R., Buzón, M. y Carrillo, J.R. (coords.) (2013-2014): Villas romanas en Andalucía. Novedades y últimos hallazgos, Romvla 12-13. Sevilla.

Higham, N. J. \& Jones, G. D. B. (1975): "Frontiers, Forts and Farmers: Cumbrian Aerial Survey 19745", Archaeological Journal 82, 16-53.

Hingley, R., (1989): Rural Settlement in Roman Britain. London.

Hopewell, D., Burman, J., Evans, J., Ward, M. \& williams, D. (20005): "Roman Fort Environs in North-West Wales", Britannia 36, 225-269.

Isla, A. (2001): "Villa, villula, castellum. Problemas de terminología rural en época visigoda. Arqueología y territorio medieval 8, 9-19.

Ivanov, T. (1973): "Neuentdeckte Inschriften über die Bautätigkeit Neros in Thraktien", Archaeologia Polona 14, 209-213.

Járrega, R. (2000): “(2000) “El poblament rural i l’origen de les villae al nord-est d'Hispania durant l'època romana republicana (segles II-I aC)", Quad. Preh. Arq. Cast., 21, 271-302. 
Jiménez Cobo, M. (2000): Jaén romano. Jaén.

Jiménez Guijarro, J. (2008): "El yacimiento romano de El Beneficio (Collado Mediano, Prov. Madrid) y la mansio de Miaccum de la vía XXIV del itinerario de Antonino", Madrider Mitteilungen 49, 354-387.

Johnson, S. (1983): Late roman fortifications. London.

Kleberg, T. (1957): Hôtels, restaurants et cabarets dans l'antiquité romaine: études historiques et philologiques. Uppsala.

Lafon, X. (2001): Villa Maritima: recherches sur les Villas littorales de l'Italie romaine (IIIe siècle av.J.-C./ IIIe siècle ap. J.-C.), Bibliothèque des Écoles Françaises d'Athènes et de Rome 307. Roma.

Lazzarini, S. (2001): Lex metallis dicta: studi sulla seconda tavola di Vipasca, Minima epigraphica et papyrologica. Supplementa 2. Roma.

Le Roux, P. (1992-1993): "Vicus et Castellum en Lusitanie sous l'empire", Studia Historic, Historia Antigua 10-11, 151-160.

Le Roux, P. y Tranoy, A. (1983): “つ, le mot et la chose. Contribution au débat historiographique", Archivo Español de Arqueología 56, 109-121.

Lengrand, D. (1996): "Les notables et leurs propriétés: la formule "in his praediis" dans l'empire romain", REA 98, 109-131.

Leschi, L. (1941): "Centenarium quod «Aqua Viva» appellatur....", Comptes rendus des séances de l'Académie des Inscriptions et Belles-Lettres 85 (2), 163-176

Letta, C., (2005): "Vicus rurale e vicus urbano nella definizione di Festo (pp. 502 e 508 L.)". Rivista di cultura classica e medioevale 47 (1), 81-96.

Leveau, Ph. (1984): Caesarea de Maurétanie. Une ville romaine et ses campagnes. Roma.

Leveau, Ph. (1993): "Territorium urbis. Le territoire de la cité romaine et ses divisions: du vocabulaire aux réalités administratives", REA 3-4, 459-471.

Leveau, Ph. (1994): "La recherche sur les agglomerations secondaires en Gaule Narbonaisse", en J.J. Petit, M. Mangin y Ph. Brunella : Les agglomérations secondaires. La Gaule Belgique, les Germanies et L'Occident romanie. Paris 181-196.

Leveau, Ph. (2002): "L'habitat rural dans la Provence Antique : villa, vicus et mansio. Etudes de cas", Revue Archéologique de Narbonnaise 35, 59-92.

Leveau, Ph., Sillieres P. y Vallet J.-P. (1993): Campagnes de la Méditerranée romaine, Paris.

Leveau Ph., Gros P. y Trément, F. (1999): "La recherche sur les élites gallo-romaines et le problème de la villa", A. Antoine (dir.): Campagnes de l'Ouest. Stratigraphies et relations sociales dans l'histoire, Colloque de Rennes 24-26 mars 1999, Rennes, 287-302.
Levi, A. (1967): Itineraria picta: contributo allo studio della Tabula Peutingeriana, Roma.

Lewit, T. (2004): Villas, farms and the late roman rural economy (third to fifth centuries $A D$ ), BAR Int.Series, 568. Oxford. (ed. revisada y actualizada de Lewitt, 1991).

Loewinsohn, E. (1999): "La A1 entre Lancia y Ad Legio VII", El miliario extravagante 71, 11-12.

Lopes, M. C. (2003): A cidade romana de Beja. Percursos e debates acerca da "civitas" de Pax Iulia. Coimbra.

López Ambite, F. (2009): “Continuidad y cambio en los asentamientos rurales romanos del nordeste de la provincia de Segovia", Lvcentvm XXVIII, 111146.

López Barja, P. (1999): "El censo provincial de рориli y castella de Gallaecia" Gallaecia 18, 347-362.

Lopez Quiroga, J. y Rodriguez Martín, G. (20002001): "El final de las villae en Hispania I. La trasnformación de la pars urbana de las villae durante la antigüedad tardía" Portugalia XXIXXII, 137-190.

MacDonald, W. L. y Pinto, J. A. (1995): Hadrian's Villa and its Legacy. New Haven.

Macias Solé, J. M. y Menchon, J. (eds.) (2007): La vil.la romana dels Hospitals (el Morell, Tarragona) Un assentament de la via "De Italia in Hispanias", Hic et nunc 1. Tarragona.

Macías, F. R. (2008): "Vici y articulación del territorium: Segobriga, Ercauica y Valeria", en J. Mangas y M. A. Novillo (eds.): El territorio de las ciudades romanas. Madrid, 617-634.

Martínez Gázquez, J. (2008): “Les villae romanae en els textos literaria”, en J. A. Remolá (dir.): $E l$ territorio de Tarraco: vil.les romanes del Camp de Tarragona. Tarragona, 9-21.

Martínez Melón, J. I., (2006): "El vocabulario de los asentamientos rurales (siglo I-IX d.C.): Evolución de la terminología". En Chavarría, A., Arce, J. y Brogiolo, G. (eds.): Villas Tardoantiguas en el Mediterráneo Occidental. Anejos de Archivo Español de Arqueología 39. Madrid, 113-132.

Martins, M. y Carvalho, H. P. (2010): "Bracara Augusta and the changing rural landscape", en C. Corsi y F. Vermeulen (eds.): Changing Landscapes. The impact of roman towns in the Western Mediterranean. Bolonia, 281-298.

Martins, M., Sande Lemos, F. y Pérez Losada, F. (2005): "O povoamento romano no territorio dos Galaicos bracarenses", en C. Fernández Ochoa y P. García (eds.): Unidad y diversidad en el Arco Atlántico en época romana - vol.1 - BAR Inter. Ser. 1371, 279-296. 
Marzano, A. (2007): Roman villas in central Italy a social and economic history, Columbia studies in the classical tradition 30. Leiden/Boston.

Mason, D. J. P. (1987): "Chester: The Canabae Legionis", Britannia 18, 143-168.

Massy, J.-L. (1997): Les agglomérations secondaires de la Lorraine romaine, Annales littéraires de l'Université de Besançon 647, Institut des sciences et techniques de l'antiquité 161. Paris.

Mattingly, D. J. (1995): Tripolitania. London.

Maune, S. (2000): "La question des premières installations rurales italiennes en Gaule transalpine", Gallia 57, 231-260.

Maurin, L. (dir.) (1990): Villes et agglomérations urbaines antiques du sud-ouest de La Gaule. Histoire et archéologie. 2e colloque Aquitania. Aquitania. Supplement 6. Bordeaux.

Mayer, M. y Olesti, O. (2001): "La sortitio de Ilici. Del documento epigráfico al paisaje histórico", Dialogues d'Histoire Ancienne 27/1, 109-130.

Mayoral, V. y Celestino, S. (eds.) (2010): Los paisajes rurales de la romanización: arquitectura y explotación del territorio. Madrid.

Mayoral, V. y Sevillano, L. (2013): "Prospección, paisaje y el "gran cuadro" de la historia agraria: una revisión crítica y algunas propuestas", Comechingonia. Revista de Arqueología 17, 31-56.

Mayoral, V., Bustamante, M., Martínez, J.A., Liceras, R., Mota, M., Pizzo, A., Salas, E., Sevillano, L.A. y de Soto, P. (2013): "Los paisajes agrarios de la romanización en el Suroeste peninsular. Balance de los últimos trabajos desarrollados desde el Instituto de Arqueología", en J. Jiménez Ávila, M. Bustamante y M. García (coords.): VI Encuentro de Arqueología del Suroeste Peninsular. Villafranca de los Barros, 1389-1423.

Mayoral, V., Cerrillo Cuenca, E. y Celestino, S. (2009): "Métodos de prospección arqueológica intensiva en el marco de un proyecto regional: el caso de la comarca de La Serena (Badajoz)", Trabajos de Prehistoria 66-1, 7-25.

Mellado Rodriguez, J. (1900): Léxico de los concilios visigóticos de Toledo. Córdoba.

Mezquiriz de Catalán, M. A. (2003): La villa romana de Arellano. Pamplona.

Molina Vidal, J. (2008): "La villa romana: de las fuentes escritas a la creación del concepto histórico", Actes del Simposi: Les vil-les romanes a la Tarraconense 3. Barcelona, 37-48.

Moneta, C. (2010): Der Vicus des römischen Kastells Saalburg, Saalburg.

Moreno Almenara, M. (1997): La villa altoimperial de Cercadilla (Córdoba). Análisis Arqueológico. Sevilla.
Morere Molinero, N. (1990): Las villae romanas en la Galia narbonense. Madrid.

Morillo, A. y Salido, J. (2014): "Military vici in Roman Spain”, XXII International Limes Congress, Ruse, en prensa.

Morris, P. (1979): Agricultural Buildings in Roman Britain, BAR British series 70. Oxford.

Mulvin, L. (2004): Late Roman villas in the DanubeBalkan region, BAR international series 1064. Oxford.

Noguera Celdrán, J. M. (coord.) (1995): Poblamiento rural romano en el Sureste de Hispania. Murcia.

Noguera Celdrán, J. M. (coord.) (2010): Poblamiento rural romano en el Sureste de Hispania: 15 años después. Murcia.

Núñez, J. y Aquilué, X. (2006): “El proyecto Mariturri (Vitoria/Gasteiz). De la excavación a la presentación de una mutatio y un vicus relacionados con la calzada Astorga-Burdeos", III Congreso Internacional sobre musealización de yacimientos arqueológicos. Zaragoza, 330-332.

Núñez, J. y Sáenz de Urturi, J. P. (2005): “Una mutatio de la via $A b$ Asturica Burdigalam en Mariturri (Vitoria/Álava)", Archivo Español de Arqueología 78, 189-207.

Olesti Vila, O. (1995): El territori del Maresme en época republicana (s. III-I a.C.): estudi d'arqueomorfología i història. Mataró.

Olesti Vila, O. (1997): "El origen de las villae romanas en Cataluña”, Archivo Español de Arqueología 70, 71-90.

Olesti Vila, O. (2008): "Formas de propiedad y gestión de la tierra en la Colonia Barcino", en J. Mangas y M. A. Novillo (eds.): El territorio de las ciudades romanas. Madrid, 279-308.

Olesti Vila, O. (2010): “Urbanització, integració i gestió del territori al N.E. de la Península ibèrica en època republicana (s. II-I a.C.)", Time of changes. In the beginning of the Romanization. Studies on the rural world in the Roman Period 5. Girona, 11-60.

Olesti Vila, O. (2013): "La organización territorial de la colonia Barcino: posibilidades y límites de los estudios catastrales", en R. Cid y E. García Fernández (eds.): Debita verba: estudios en homenaje al profesor Julio Mangas Manjarrés, vol. II, 75-91.

Olesti, O., Mercadal, O. y Valiente, P. (2005): “La Cedanya i els ceretans: transformacions d'un poble i d'un paisatge pirinenc en època antiga", en $\mathrm{O}$. Mercadal (ed.): Món ibèric: als Països Catalans: XIII Col.loqui Internacional d'Arqueologia de Puigcerdà: homenatje a Josep Barberà i Farràs, Puigcerdà, vol. 1, 287-312. 
Oliveira, C. F. de (2003), A villa romana de Rio Maior: estudo de mosaicos, Trabalhos de arqueologia 31. Lisboa.

Oller, J. (2013): El territori i poblament del Vallès en época antiga Del sorgiment de la societat ibèrica a la romanització (ss. VI $a C$. - II $d C$.). Estudi arqueomorfològic $i$ històric, Universidad Autónoma de Barcelona, Tesis Doctoral. Bellaterra.

Orejas, A (1996): Estructura social y territorio. El impacto romano en la cuenca noroccidental el Duero, Anejos de Archivo Español de Arqueología 15. Madrid.

Orejas, A (2005): "El poblamiento romano en los distritos mineros del Noroeste", en C. Fernández Ochoa y P. García (eds.): Unidad y diversidad en el Arco Atlántico en época romana - vol.1 - BAR Inter. Ser. 1371, 309-322.

Orejas, A (2006): “Arqueología de los paisajes agrarios e historia rural", en A. Orejas (coord.): Arqueología Espacial: Espacios agrarios, Arqueología Espacial 26. Teruel, 7-19.

Orejas, A (2008): "Investigando el paisaje", en M. Mas y M. Zarzalejos (coords.): El Presente de la Arqueología, A Distancia 23, 79-85.

Orejas, A. (1991): “Arqueología del paisaje: historia, problemas y perspectivas", Archivo Español de Arqueología 64, 191-230.

Orejas, A. y Ramallo, S. (2005) : “Carthago Noua: La ville et son territoire. Recherches récentes", De la terre au ciel. Paysages et cadastres antiques. Besançon, 87-120.

Orejas, A. y Ruiz del Árbol, M. (2010): "Los castella y la articulación del poblamiento rural de las "civitates" del Noroeste peninsular", en C. Fornis, J. Gállego P.M. y López Barja (coords.): Dialéctica histórica y compromiso social, vol. 2, 1091-1128.

Orejas, A. y Sastre, I. (1999): "Fiscalité et organisation du territoire dans le Nord-Ouest de la Péninsule Ibérique: civitates, tribut et ager mensura comprehensus", Dialogues d'histoire ancienne 25.1, 159188.

Orejas, A.y Sastre, I. (2003) : "L`Ager mensura comprehensus et le sol provincial : L'Occident de la Péninsule Ibérique "en Conso, D., González, A. y Guillaumin J.Y. (eds) : Les vocabulaires techniques des arperteurs romains. Besançon, 193-199.

Orengo, H. (2010): Arqueología de un paisaje cultural pirenaico de alta montaña. Dinámicas de ocupación del valle del Madriu-Perafita-Claror (Andorra), Universidad Rovira y Virgili, Tesis Doctoral. Tarragona.

Ortalli, J. (ed.) (2006): Vivere in villa. Le qualità delle residenze agresti in età romana, Atti del Convegno di Ferrara. Florencia.
Ossel, P. Van, (1992): Etablissements ruraux de l'Antiquité tardive dans le nord de la Gaule. Paris.

Ouzoulias, P., Pellecuer, C., Raynaud, Cl. y Van Ossel, P. (dirs.) (2001): Les campagnes de la Gaule à la fin de l'Antiquité, Colloque international AGER IV, Montpellier, Antibes.

Palet, J. M. (1997): Estudi territorial del Pla de Barcelona. Estructuració $i$ evolució del territori entre l'epoca iberoromana i altmedieval. Segles III a.C.-X-XI d.C. Barcelona.

Palet, J. M. (2003): “L'organització del paisatge agrari al Penedès i les centuriacions del territori de Tarraco: Estudi arqueomorfològic", en J. Guitart, J. M. Palet y M. Prevosti (eds.): Territoris antics a la Mediterrània i a la Cossetania oriental. Barcelona, 211-229.

Palet, J. M. (2005a): "L'estructuració dels espais agraris en época romana a Catalunya: aportaciones de l'estudi arqueomofològic del territorio", Cota Zero 20, 53-66.

Palet, J. M. (2005b): "Estructuras agrarias en el territorio de Tarraco (Tarragona): organización y dinámica del paisaje en época romana", en A. Bouet y F. Verdin (eds.): Territoires et paysages de l'age du fer au Moyen Âge: Mélanges offerts à Philippe Leveau. Burdeos, 213-226.

Palet, J. M. y Orengo, H. (2010): "Les centuriacions de l'ager tarraconensis: organització i concepcions de l'espai", en M. Prevosti y J. Guitart (eds.): Ager Tarraconensis 1. Aspectes històrics i marc natural. Tarragona, 121-154.

Palet, J. M., Fiz, J. I. y Orengo, H. (2009): “Ceturiació i estructuració de l'ager de la colònia Barcino: anàlisi arqueomorfològica i modelació del paisatge", Quarhis, época II, 5, 106-123.

Palet, J. M., Fiz, J. I. y Orengo, H. (2010): "Modelización y conceptualización del paisaje en el ager Tarraconensis: Tarraco y la centuriación del territorio", en C. Corsi y F. Vermeulen (eds.): Changing Landscapes. The impact of roman towns in the Western Mediterranean. Bolonia, 167-184.

Palet, J. M., Orengo, H. Ejarque, A., Miras, Y. y Riera, S. (2013): “Arqueología de paisajes altimontanos pirenaicos: formas de explotación y usos del medio en época romana en valle del Madriu-PerafitaClaror (Andorra) y en la Sierra del Cadí (Alt Urgell)", en J.L. Fiches, R. Plana y V. Revilla (eds.): Paysages ruraux et territoires dans les cités de l'occident romain. Gallia et Hispania, Actes du colloque International Ager IX. Barcelona, 329-340.

Pellecuer, Ch. (2000): La” villa" des Prés-Bas (Loupian, Hérault) dans son environnement. Contribution à l'ètude des villae et de l'économie domaniale en Narbonnaise. Aix-Marseille. 
Pellecuer, Ch. (dir.) (1994): Formes de l'habitat rural en Gaule Narbonnaise, 2, Juan-Les-Pins.

Pensabene, P. (2010): Piazza Armerina Villa del Casale e la Sicilia tra Tardoantico e Medioevo, Studia archaeologica 175. Roma.

Pensabene, P. (coord.) (2012) La villa restautarata e nuovi stidi sull edilizia residenciale tardoantica, CISEM. Piazza Armerina, Sicilia (en prensa).

Pensabene, P. y Girón, L. (coord.) (2012): I Seminario sobre Villas Tardoantiguas. Arquitectura y cultura material. Cádiz.

Peña Cervantes, Y. (2010): Torcularia. La producción de vino y aceite en Hispania, Documenta 14. Tarragona.

Pereira Menaut, G. (1982): "Los castella y las comunidades de Gallaecia", II seminario de Arqueología del Noroeste. Madrid.

Pérez Ballester, J.y Arasa, F. (2010): "Poblament rural i vies de comunicaió en època romana a la Ribera del riu Xúquer (València)", Recerques del Museu d'Alcoi 19, 101-114.

Pérez Losada, F. (1987): "Sobre o concepto de 'villa' no mundo romano". Cadernos de arqueología 4, 79-109.

Pérez Losada, F. (1996): "Hacia una definición de los asentamientos rurales en la Gallaecia: poblados (vici) y casas de campo (villae)". En Fernandez Ochoa, C., (coord.): Los finisterres atlánticos en la antigüedad: época prerromana y romana. Gijón, 189-200.

Pérez Losada, F. (2002): Entre a Cidade e a Aldea: estudio arqueohistórico dos "aglomerados secundarios" romanos en Galicia. Brigantium 13. A Coruña.

Pérez Macías, J. A. y Delgado, A. (2012): "Paisaje y territorio de Riotinto en época romana”, en M. Zarzalejos, P. Hevia y L. Mansilla (eds.): Paisajes mineros antiguos en la Península Ibérica. Investigaciones recientes y nuevas líneas de trabajo. Homenaje a Claude Domergue. Madrid, 47 68.

Pérez Macias, J.A., Martins, A. Bustamante, M. y Delgado, A. (2009): "De Praesidium a vicus metallum: el poblado minero en el suroeste peninsular" en González, J. y Pavón, P. (eds.), Andalucia romana y visigoda. Ordenación y vertebración del territorio. Roma, 37-64.

Pérez Ruiz, M. (2010): “Aproximación al culto doméstico en la Hispania romana. Algunas consideraciones", Bolletino di Archeologia online 2010, 107-114.

Petit, J.-P. y Mangin, M. (1994): Atlas des agglomérations secondaires: de la Gaule Belgique et des Germanies. Paris.
Petit, J.-P. y Mangin, M. (1994): Les agglomérations secondaires: La Gaule Belgique, les Germanies et l'Occident romain. Actes du colloque de Bliesbruck-Reinheim, Bitche (Moselle), 21, 22, 23 et 24 octobre 1992. Paris.

Picard, G.-C. (1970): "Les conciliabula en Gaule", BSNAF 1970, 66-69.

Plana, R. (2002): "Le territoire d'Ebora en Lusitanie", en M. Clavel-Lévêque y A. Orejas (dir.): Atlas historique des cadastres d'Europe II, dossier 7. Luxembourg.

Plana, R. y Revilla, V. (2007): “Les formes de 1'habitat rural et les rythmes de l'occupation des campagnes ibériques et romaines dans la zone centrale et septentrionales de la côte catalane", en $\mathrm{Ph}$. Leveau, C. Raynaud, R. Sablayrolles y F. Trément (eds.): Les formes de l'habitat rural gallo-romain. Terminologie et typologie à l'épreuve des réalités archéologiques. Bordeaux, 333-345.

Ponsich, M. (1974): Implantation rurale antique sur le Bas-Guadalquivir. Madrid.

Ponsich, M. (1979): Implantation rurale sur le BasGuadalquivir, 2. La Campagna. Palma del Río. Posadas. Paris.

Ponsich, M. (1987): Implantation rurale antique sur le Bas-Guadalquivir, 3. Bujalance, Montoro, Andújar. Madrid.

Portela Filgueiras, M. I. (1984): "Los dioses lares en la Hispania romana", Lucentum 3, 153-180.

Poulter, A. (1989): "Gli insediamenti presso i campi military: "canabae" e "vici", J. Wacher (ed.), Il mondo di Roma imperial. Vita urbana e rurale II. Bari, 69-106.

Poveda Navarro, A. M. (2002): "Fora Hispania: La evidencia de Libisosa Forum Augustum (Lezuza, Albacete)", Conimbriga 41, 5-28.

Prevosti, M. (1981 a): Cronología i poblament a l'àrea rural de Baetulo. Barcelona.

Prevosti, M. (1981 b): Cronología i poblament a l'àrea rural de Iluro. Mataró.

Prevosti, M. (1996): Formes de l'habitat rural en Gaule Narbonnaise, 3. Juan-Les-Pins.

Prevosti, M. y Guitart, J. (dirs.) (2010): Ager Tarraconensis 2. El poblament, Documenta 16, ICAC. Tarragona.

Prevosti, M., López Vilar, J. y Guitart, J. (dirs.) (2010): Ager Tarraconensis 5. Paisatje, poblament, cultura material $i$ historia. Actes del Simposi internacional. Tarragona.

Prieto, A., Cortadella, J., y Olesti, O. (2001): "Aproximación a la organización territorial de la Depresión de Antequera en época romana", en F. Wulff, G. Cruz y Martínez Maza (eds.): Comercio y comerciantes en la Historia Antigua de Málaga. Málaga, 627-638. 
Pucci, G. (1989): "Le iscrizioni di M. Cincius Hilarianus", VV.AA., Il castellum del Nador. Storia di una fattoria tra Tipasa e Caesarea (I VI sec. d.C.), Monografie di Archeologia Libyca XXIII. Roma, 111-118.

Purcell, N. (1995): "The Roman villa and the landscape of production", en T. J. Cornell y K. Lomas (eds.): Urban Society in Roman Italy. London, 151179.

Réchin, F. (ed.) (2006): Nouveaux regards sur les Villae d'Aquitaine: bâtiments de vie et d'exploitation, domaines et postérités médiévales. Actes de la Table-Ronde de Pau, 24-25 novembre 2000, Archéologie des Pyrénées occidentales et des Landes 2. Pau.

Reddé, M. (1995): "Les agglomérations secondaires en Gaule", JRA 8, 511-513.

Reddé, M. et alii (2006): L'architecture de la Gaule romaine. Paris.

Reddé, M. y Golvin, J. C. (1987): “Du Nil à la mer Rouge: documents anciens et noveaux sur les routes du désert oriental d’Égypte", Karthago XXI, 5-64.

Reddé, M. (1995): "Diocletien et les fortifications militaires de l'Antiquite Tardive", Antiquité tardive 3, 91-124.

Regueras, F. (2013): Villas romanas del Duero. Historia de un paisaje olvidado. Valladolid.

Remolà Vallverdú, J. A. (2007): El territori de Tarraco villes romanes del Camp de Tarragona, Forum: temes d'història d'arqueologia tarragonines 13. Tarragona.

Requejo, O. (2014): Arqueología y territorio en el sector central de Asturias: la cuenca del río Nora entre el periodo tardorromano y la antigüedad Tardía (siglo IV-inicios del siglo VIII d-C.), Tesis Doctoral, Universidad de Oviedo. Oviedo.

Requejo, O. y Gutiérrez González, A. (2009): “El asentamiento altomedieval de la vega de Corao (Cangas de Onis, Asturias, España)" en J. A. Quirós Castillo: The archaeology of early medieval villages in Europa. Vitoria-Gasteiz, 167-180.

Revilla, V. (1992-1994): "Poblamiento y economía en el bajo Ebro en época romana: bases para un modelo de paisaje rural", Lucentum 11-13, 145-163

Revilla, V. (2004): “El poblamiento rural en el noreste de Hispania entre los siglos II a. C. y I d. C.: organización y dinámicas culturales y socioeconómicas", P. Moret y T. Chapa (coords.): Torres, atalayas y casas fortificadas: explotación y control del territorio en Hispania (s. III a. de C.- $s$. I d. de C.). Madrid, 175-204.

Revilla, V. (2010): "Hábitat rural y territorio en el litoral oriental de "Hispania Citerior": perspectivas de análisis”, en J. M. Noguera Celdrán (ed.):
Poblamiento rural romano en el sureste de Hispania15 años después. Murcia, 25-70.

Revilla, V., González, J.R. y Prevosti, M. (eds.) (2008): Simposi les vil.les romanes a la Tarraconense. Implantació, evolució i transformació. Estat actual de la investigació del món rural en època romana. Vol. I, Barcelona.

Revilla, V., González, J.R. y Prevosti, M. (eds.) (2011): Simposi les vil-les romanes a la Tarraconense. Implantació, evolució i transformació. Estat actual de la investigació del món rural en època romana. Vol. II. Barcelona.

Rivet, A. L. F. (1969): The Roman Villa in Britain. New York.

Rodríguez Colmenero, A., Ferrer Sierra, S. y Hervés Raigoso, F. (1999): "El complejo arqueológico romano de "Aquis Querquennis": Porto Quintela (Ourense)", Los orígenes de la ciudad en el noroeste hispánico. Actas del Congreso Internacional, vol. 2, Lugo, 891-910.

Rodríguez Resino, A. (2007): “Ciudades, vicus, castra y villae en el NW durante la tardoantigüedad: ensayo de un modelo arqueológico para el período", Gallaecia 26, 133-161.

Rodríguez, S. y Barrio, C. (2003): "Poblamiento tardorromano en el valle medio del río Guadarrama (Toledo)", Bolskan 20, 267-275.

Rorison, M. (2001): Vici in Roman Gaul. Oxford.

Rossiter, J. J. (1981): "Wine and oil processing at Roman farms in Italy”, Phoenix 35, 345-362.

Rovira i Port, J. y Gasca Colobrans, M. (1990): "Una Statio con restos de una Turris, en el Tossal de Cal Montblanc (Albesa, La Noguera, Lleida), y su vía romana", Simposio sobre la red viaria en la Hispania romana. Zaragoza, 385-398.

Ruiz Zapatero, G. y Burillo Mozota, F. (1988): "Metodología para la investigación en arqueología territorial", Munibe (Antropología y Arqueología) sup.6, 45-64.

RUST, T. C. (2006): Architecture, economics, and identity in Romano-British 'Small towns', BAR international series 1547. Oxford.

Sáez, P., Ordóñez, S. y García-Dils, S. (2002): "Le territoire d'Astigi (Ecija). La centuriacion”, en M. Clavel-Lévêque y A. Orejas (dir.): Atlas historique des cadastres d'Europe II, dossier 2. Luxembourg.

Salido Domínguez, J. (2003-2004): "La documentación literaria aplicada al registro arqueológico: las técnicas de construcción de los graneros romanos rurales", Espacio, Tiempo y Forma. Serie I: Prehistoria y Arqueología 16-17, 463-478.

Salido Domínguez, J. (2008): "Los sistemas de almacenamiento y conservación de grano en las villae 
hispanorromanas", C. Fernández Ochoa, V. GarcíaEntero y F. Gil Sendino, (eds.): Las villae tardorromanas en el Occidente del Imperio. Arquitectura y función. IV Coloquio Internacional de Arqueología de Gijón. Gijón, 693-706.

Sánchez-Palencia, F. J. (coord.) (2000): Las Médulas (León): un paisaje cultural en la Asturia Augustana. León.

Sanchez-Palencia, F.J. Sastre, I, Romero, B., Pecharromán, J-L-, Alonso,,F., Currás,B.X. y Reher, G.S. (2010): “La zona minera de Pino del Oro (Zamora), un paisaje rural de época romana" en C. Fornis, J. Gallego, P. López-Barja y M. Valdés (eds.) Dialectica histórica y compromiso social. Homenaje a Domingo Plácido. Madrid, 1067-1090.

Sánchez-Palencia, F.J. y Ruiz del Árbol, M. (2000): "Estructuras agrarias y explotación minera en Lusitania nororiental: la zona Arqueológica de Les Cavenes (El Cabaco, Salamanca)", en J.G. Gorges y T. Nogales (coords.): Sociedad y cultura en la Lusitania romana. Mérida, 343-360.

Sánchez-Pardo, J.C. (2010): “Castros y aldeas galaicorromanas: sobre la evolución y transformación del poblamiento indígena en la Galicia romana", Zephyrvs LXV, 129-148.

Sastre, I. (2001): Las formaciones rurales de la Asturia prerromana. Madrid.

Sfameni, C. (2006): Ville residenciali nell'Italia Tardoantica. Roma.

Smith, D. J. (1985): “The Centenaria of Tripolitania and their antecedents", Libya in History, 299-309.

Smith, J. T. S. (1997): Roman Villas: A Study in Social Structure. London.

Sommer, C. S. (1984): The military vici in Roman Britain: aspects of their origins, their location and layout, administration, function, and end, BAR British Series, 129 Oxford.

Soren, D. y Soren, N. (1999): A Roman Villa and a Late Roman Infant Cemetery: Excavations at Poggio Gramignano Lugnano in Teverina. Roma.

Sternini, M. (2000): La villa romana di Cottanello, Bibliotheca archaeologica 8. Bari.

Tarpin, M. (1999): “Oppida ui capta, uici incensi... Les mots latins de la ville”. Latomus 58 (2), 279-297.

Tarpin, M. (1999): “Oppida ui capta, uici incensi... Les mots latins de la ville”. Latomus 58 (2), 279-297

Tarpin, M. (2002): Vici et pagi dans loccidente romain. Roma.

Teichner, F. y Schierl, T. (2010): “Asentamientos rurales en el sur de la Lusitania entre la fase tardo-republicana y el inicio de la época imperial romana», en V. Mayoral Herrera y S. Celestino Pérez (ed.), Los paisajes rurales de la romanización. Arquitectura y explotación del territorio. Madrid, 89-114.

Teja, R. (1990): "La carta 67 de San Cipriano a las comunidades cristianas de León-Astorga y Mérida: algunos problemas y soluciones", Cristianismo y aculturación en tiempos del Imperio Romano, Antigüedad y Cristianismo VII, 115-124.

Teja, R. (2005): “Ad Legionem consistentibus: las canabae de la Legio VII en una Epístola de San Cipriano de Cartago", en C. Pérez González y E. Illarregui (coords.), Arqueología militar romana en Europa, Segovia, 305-307.

Thomas, R. y Wilson, A. (1994): "Water supply for Roman farms in Latium and South Etruria", PBSR 62, 139-198.

Todd, M. (1970): "The Small Towns of Roman Britain", Britannia 1,114-130.

Uggeri, G. (1995): "Le stazioni postali romane nella terminologia tardoantica", R. Bedon y P. M. Martin (eds.): Mélanges Raymond Chavellier II, 2, Caesarodunum XXIX, 137-144.

Urbina, D. (1999): "Introducción al poblamiento romano en el valle bajo del río Alberche. Toledo", Stvdia Historia. Historia Antigua 17, 371-394.

Urbina, y Morin, J. (eds.) (2013) : Madrigueras II. Un vicus en el territorio segobrigense, MArq Audema 2011, Madrid.

Uroz Rodriguez, H. (2012): "La colonia romana de Libisosa y sus precedentes" La ciudad romana en Castilla-La Mancha. Cuenca.

Van der Veen, M. (1992): Crop Husbandry Regimes: An Archaeobotanical Study of Farming in Northern England 1000 BC-AD 500. Sheffield.

Van Dommelen, P. (1993): "Roman peasants and rural organization in Central Italy: an archaeological perspective", TRAC 1, 167-186.

Van Ossel, P. (1992): Établissements ruraux de l'Antiquité tardive dans le nord de la Gaule, 51e suppl. à Gallia, Paris.

Vaquerizo Gil, D. y Noguera Celdrán, J. M. (1997): La villa romana de El Ruedo (Almedinilla, Córdoba): decoración escultórica e interpretación. Murcia.

Vaquerizo, D., Murillo, J. F. y Quesada, F. (1991): "Protohistoria y romanización y romanización en la Subbética Cordobesa: avance de los resultados obtenidos en las prospecciones arqueológicas desarrolladas hasta 1990", Antiquitas 2, 3-16.

Vaquerizo, D., Murillo, J. F. y Quesada, F. (1992): "Protohistoria y romanización y romanización en la subbética cordobesa: investigación arqueológica hasta 1991, Antiquitas, 3, 36-45.

Venditti, C.P. (2011): Le ville del Latium adiectum. Aspetti residenziali dell propietà rurali. Bologna. 
Vigil-Escalera Guirado, A. (2007): “Granjas y aldeas tardoantiguas y altomedievales de la Meseta. Configuración espacial, socioeconómica y política de un territorio rural al norte de Toledo (ss. V-X d. C.)", Archivo Español de Arqueología 80, 239-284.

Vittinghoff, F. (1970): “Die Entstehung von städischen Germeinwesen in der Nachsbarschaft römischer Legionslager. Ein vergleich Leóns mit den Entwickklungslinien im Imperium Romanum”, Legio VII Gemina, León, 339-352.

Vittinghoff, F. (1971): "Die rechtliche Stellung der canabae legionis und die Herkunftsangabe castris", Chiron I, 299-318.

Volpe, G (1992): Paesaggio agrario, produzione e scambi nell'A Apulia tardoantica. San Marino.

VV. AA. (1980): La villa romana de Torre Llauder, Opuscle 1. Mataró.

VV. AA. (1992): Villes et agglomérations urbaines antiques du sud-ouest de la Gaule. Histoire et archéologie, deuxième colloque Aquitania, Bordeaux, 13-15 septembre 1990, Aquitania. Supplément 6. Burdeos.

VV. AA. (1995): Las villas romanas de Madrid en época romana. Madrid.

VV. AA. (2001): Les excavacions de 1985-1989 i 1992 a la villa romana dels Atmellers, Tossa (Selva). Barcelona.
Wacher, J. (1974): The Towns of Roman Britain, Batsford.

White, K. D. (1970): Roman Farming. London

Whittaker, C. R. (ed.) (1988): Pastoral Economies in Classical Antiquity. Cambridge.

Wright, R. P. (1956): "Roman Britain in 1955: I. Sites Explored: II. Inscriptions", Journal of Roman Studies 1956, 119-152.

Zarzalejos, M., Esteban, G., Mansilla, L., Palero, F., Hevia, P. y Sánchez Vizcaíno, J. (2012): "Nuevas aportaciones al conocimiento del paisaje minero antiguo en la vertiente norte de Sierra Morena: del análisis macroespacial al estudio de detalle", en M. Zarzalejos, P. Hevia y L. Mansilla (eds.): Paisajes mineros antiguos en la península ibérica. Investigaciones recientes y nuevas líneas de trabajo. Homenaje a Claude Domergue. Madrid, 123153.

Zarzalejos, M., Fernández Ochoa, C., Esteban, G. y Hevia, P. (2012): "El paisaje minero antiguo de la comarca de Almadén (Ciudad Real). Nuevas aportaciones sobre el territorium de Sisapo", en A. Orejas y Ch. Rico (eds.): Minería y metalurgia antiguas. Visiones y revisiones. Casa de Velázquez 128, Madrid, 129-150. 